\title{
Modeled mixed-layer salinity balance in the Gulf of Guinea: seasonal and interannual variability
}

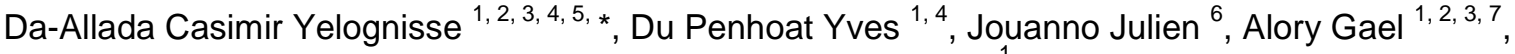 \\ Hounkonnou Norbert Mahouton ${ }^{1}$
}

${ }^{1}$ Univ Abomey Calavi, Int Chair Math Phys \& Applicat, ICMPA UNESCO Chair, Cotonou, Benin.

${ }^{2}$ Univ Toulouse, F-31400 Toulouse, France.

3 IRD, LEGOS, F-31400 Toulouse, France.

${ }^{4}$ IRHOB, Cotonou, Benin.

${ }^{5}$ Ifremer, LPO UMR 6523, CNRS/Ifremer/IRD/UBO, Plouzané, France

${ }^{6}$ CICESE, Dept Oceanog Fis, Ensenada, Baja California, Mexico.

${ }^{7}$ LEGOS, CNAP, Toulouse, France.

*Corresponding author : Casimir Yelognisse Da-Allada, email address : daallada@yahoo.fr

\begin{abstract}
:
A regional numerical simulation and observations were used to investigate the various processes controlling mixed-layer salinity balance on seasonal and interannual time scales in the Gulf of Guinea. Processes were quantified using a mixed-layer salt budget. Model results correctly reproduced the mean, phase, and amplitude of observed seasonal near-surface salinity. The results indicated that on seasonal time scales, the mixed-layer salinity balance differed from one region to another. The surface salinity seasonal cycle was characterized by strong salinization during May for coastal areas north and south of the equator. Model results suggested that vertical mixing controls the mixed-layer salinity increase at the equator during May, while both vertical mixing and vertical advection contribute to the salinity increase in coastal regions. We also determined that freshening from horizontal advection and freshwater flux tended to balance the salinization effects of vertical diffusion and vertical advection during the seasonal cycle. On interannual time scales, based on the mixed-layer salinity balance and sensitivity experiments, we determined that for the northern and equatorial Gulf of Guinea, changes in near-surface salinity were largely due to changes in precipitation and winds. For the southern Gulf of Guinea, only wind changes were determined to be important for explaining near-surface salinity changes.
\end{abstract}

Keywords : Sea surface salinity, Gulf of guinea, Model, Mixed-layer budget, Seasonal variability, Interannual variability 


\section{Introduction}

The mean distribution and variability of ocean salinity are important for understanding the role of the ocean in climate as well as changes in the hydrological cycle, a key component of the climate system (Webster, 1994; Yu, 2011). Due to the barrier layer process that reduces the entrainment of cool thermocline water into the mixed layer, salinity may impact the exchange of heat between warm surface layers and colder subsurface layers in the tropical ocean. As a result, salinity may influence heat flux between the upper ocean and the atmosphere (Lukas and Lindstrom, 1991; Sprintall and Tomczak, 1992).

Upper water layers within the Gulf of Guinea region receive significant amounts of freshwater. The Congo River (the second largest river in the world after the Amazon River for freshwater discharge), located in the south, and the Niger River, located in the north, discharge important quantities of freshwater to the coast. The region is also under the influence of the Inter-Tropical Convergence Zone (ITCZ) that brings strong seasonal precipitation to the region. Together, these factors may contribute to the formation and variability of a barrier layer. In a model study, Jouanno et al. (2011) determined that strong stratification caused by the presence of low-salinity waters inhibits vertical mixing at the base of the mixed-layer in the Gulf of Guinea, and may contribute to the maintenance of warm conditions at the surface. Based on observations, Materia et al. (2012) suggested that the modulation of freshwater input in the eastern equatorial Atlantic Ocean and the formation of barrier layers may participate in the inter-annual variability of Sea Surface Temperature (SST) within the region. Tzortzi et al. (2013), using recent observations from SMOS satellite (Soil Moisture - Ocean Salinity), suggested the importance of the dynamical terms (advection and mixing) in explaining the seasonal cycle of Sea Surface Salinity (SSS) in the eastern tropical 
72 Atlantic Ocean, where no clear relationship between SSS and surface forcing terms was established.

To describe and to understand the physical processes responsible for SSS variations in the Gulf of Guinea region, several studies have been performed based on observations and models. Dessier and Donguy (1994) used observations collected from research vessels and Voluntary Observing Ships (VOS) to investigate the causes of SSS variations in the tropical Atlantic Ocean and concluded that, within the eastern Atlantic Ocean, precipitation associated with the ITCZ largely controls SSS seasonal variations. However, the study did not explicitly estimate contributions from horizontal or vertical salinity advection. Reverdin et al. (2007) used SSS observations collected between 1977 and 2002 to reveal large-scale SSS variability in the tropical Atlantic Ocean. Using monthly maps of SSS, they observed that seasonal SSS variability is maximum in the eastern Gulf of Guinea. Da-Allada et al. (2013) developed a mixed-layer salinity model, forced by a combination of satellite products, atmospheric reanalyses, and in situ observations to diagnose seasonal SSS variations in the tropical Atlantic Ocean. Five different regions were investigated and the authors concluded that the salinity balance was different for each region. Results were compared to a new in situ SSS gridded product for the Atlantic Ocean that covered the Argo period. The model was found to generally agree with observations in the tropical Atlantic Ocean, with the exception of the Gulf of Guinea region where the observed seasonal evolution of mixed-layer salinity was not successfully reproduced. Such discrepancies have been attributed to the model formulation that does not take into account vertical diffusion processes. Obtaining the correct balance for near surface salinity in the Gulf of Guinea likely requires an Ocean General Circulation Model (OGCM) that accurately represents vertical diffusion processes. Berger et al. (2014), using an OGCM simulation, investigated the relative impact of precipitation and river runoff 
on SSS and noted an important role of vertical diffusion on the SSS seasonal cycle within the eastern equatorial Atlantic Ocean.

The goal of the present study is to revisit the main mechanisms responsible for SSS variability in the Gulf of Guinea on seasonal and interannual time scales, from 1993 to 2009, using an OGCM to complete a previous investigation (Da-Allada et al, 2013). Our regional numerical simulation and the observations we used besides are described in Section 2. Section 3 provides results, including model validation, SSS variability on seasonal time scales, and processes for SSS interannual variability. In particular, simulated variability for both SSS and its tendencies were validated against observations. Special attention was given to the equatorial region and two coastal regions where river runoff of the Niger and Congo Rivers are particularly significant. Section 4 provides a summary and a discussion of the most important results.

\section{Model and data}

\subsection{Model description}

Our model configuration was based on the NEMO (Nucleus for European Models of the Ocean) ocean general circulation modeling system (Madec, 2008) and solves threedimensional primitive equations in spherical coordinates discretized on a C-grid and at fixed vertical levels. The model's design is based on the tropical Atlantic Ocean regional configuration on a quarter degree horizontal resolution and contains 75 levels in the vertical (with 24 levels within the upper 100 meters). The model is forced at its boundaries $\left(20^{\circ} \mathrm{S}\right.$ $20^{\circ} \mathrm{N}$ and $60^{\circ} \mathrm{W}-15^{\circ} \mathrm{E}$ ) by radiative open boundary conditions given by outputs from the global interannual experiment ORCA025-MJM95, developed by the DRAKKAR team (Barnier et al., 2006). Vertical turbulent mixing is parameterized using a level-1.5 turbulence 
119 closure scheme, with a prognostic equation for Turbulence Kinetic Energy (TKE) and a 120 diagnostic equation for length scale (Blanke and Delecluse, 1993).

121 The atmospheric fluxes of momentum, heat, and freshwater are provided by bulk formulae 122 (Large and Yeager, 2004) and ERA-Interim reanalysis (3-hour fields for wind, atmospheric 123 temperature, and humidity; and daily fields for long and short wave radiation and precipitation) from the ECMWF (European Center for Medium-range Weather Forecasts). The product appears to be the most appropriate in terms of the freshwater budget within the tropical Atlantic Ocean (Da-Allada et al., 2013). Short-wave radiative forcing is modulated by

127 a theoretical diurnal cycle. The monthly climatology of continental runoff from Dai and 128 Trenberth (2002) is prescribed for surface freshwater fluxes near each river mouth. To justify 129 the use of climatological runoff, we tested different simulations (using climatological, 130 interannual, and constant river flows) and determined, as confirmed by Berger et al. (2014), 131 that the interannual variability of river outflows do not have much effect on interannual SSS 132 variability within the eastern tropical Atlantic Ocean. In this region, it should also be noted 133 that the uncertainty of runoff data on interannual time scales is high.

134 The model was initialized on 1 January 1990 using temperature and salinity outputs from the ORCA025-MJM95 global experiment for the same date then integrated from 1990 to 2009. There was no surface salinity restoring toward a climatological SSS. 3-day averaged

137 values of SSS from 1993 to 2009 were used for the analysis. The reader is referred to Jouanno 138 et al. (2013) for further details regarding parameterization and some elements of validation, 139 including comparisons with surface and in-situ observations of temperature within the Gulf of 140 Guinea. In addition to the reference simulation (REF), sensitivity experiments forced using 141 monthly precipitation climatology (P CLIM) and monthly wind climatology (V CLIM) were 142 performed to identify the role of precipitation and wind on SSS interannual variability. 
154 with

\subsection{Salinity Budget}

To investigate the role of SSS variability processes on seasonal and interannual time scales, we used a salinity budget for the ocean mixed-layer. The approach has been used for investigating processes controlling the mixed-layer temperature within the tropical Atlantic Ocean (e.g., Peter et al. 2006; Jouanno et al. 2011), or for the interannual variability of SSS within the western tropical Atlantic Ocean (Ferry and Reverdin, 2004) and the Gulf of Guinea (Berger et al., 2014).

Following Vialard et al. (2001) but applied to salinity in the model, the mixed-layer salinity evolution equation (Eq.1) can be written as follows:

$$
\partial_{t} S S S=\underbrace{-\left\langle u \partial_{x} S\right\rangle}_{A D U} \underbrace{-\left\langle v \partial_{y} S\right\rangle}_{A D V} \underbrace{-\left\langle w \partial_{z} S\right\rangle}_{A D W}+\underbrace{\left\langle D_{l}(S)\right.}_{\text {DIFL }} \underbrace{\frac{\left(k \partial_{z} S\right)_{z=-h}}{h}}_{\text {DIFV }} \underbrace{\frac{1}{h} \frac{\partial h}{\partial t}\left(S S S-S_{z=-h}\right)}_{\text {ENT }}+\underbrace{\frac{(E-P-R) S S S}{h}}_{F W F}
$$

\section{(Eq.1)}

Here $S$ is the model salinity, (u, v) are the eastward and northward components,

156 respectively, of the horizontal velocity, and $\mathrm{w}$ is the upward vertical velocity. $D_{l}(S)$ is the lateral diffusion operator, $k$ is the vertical diffusion coefficient, $h$ is the time varying mixedlayer depth, $E$ is evaporation, $P$ is precipitation, and $R$ is river runoff.

The terms in Eq.1 represent, from left to right, mixed-layer salinity tendency, zonal 160 advection (ADU), meridional advection (ADV), vertical advection (ADW), horizontal 161 diffusion (DIFL), vertical diffusion at the mixed-layer base (DIFV), mixed-layer salinity tendency due to entrainment at the mixed-layer base (ENT), and freshwater flux terms (FWF).

163 The contributions of the horizontal diffusion and entrainment terms are negligible for the mixed-layer salinity balance on seasonal and interannual time scales (see below). 
To precisely quantify the contributions of different processes to mixed-layer salinity

166

167

168

169

170

171

172

173

174

175

176

177

178

179

180

181

182

183

184

185

186

187

tendency, the mixed-layer salinity budget was computed at each time step. Mixed-layer depth

is defined by a density criterion $\left(0.03 \mathrm{~kg} \cdot \mathrm{m}^{-3}\right.$, the difference relative to the density at $\left.10 \mathrm{~m}\right)$

following de Boyer Montégut et al. (2004) in order to take into account both temperature and salinity stratifications. In the Gulf of Guinea, the mixed-layer depth is typically $20 \mathrm{~m}$. Following Foltz et al. (2004), we assumed that mixed-layer salinity is very close to SSS. Therefore, to evaluate model skill, simulated mixed-layer salinity was compared to observed SSS.

\subsection{The in-situ SSS dataset}

The observed SSS product is an updated version of the Reverdin et al. (2007) dataset, extended to 2009 and described in Da-Allada et al. (2013). Monthly SSS were gridded using objective mapping (Bretherton et al., 1976) at a $1^{\circ} \times 1^{\circ}$ spatial resolution by compiling a variety of data sources, mostly from underway thermosalinographs on research vessels and voluntary observing ships from Pilot Research Moored Array in the Tropical Atlantic (PIRATA) moorings, surface drifters, and Argo floats. We choose this product as a reference for model evaluation since, to our knowledge, it is the most complete and up-to-date SSS product available for the tropical Atlantic Ocean basin.

\subsection{Drifter surface currents}

To validate surface currents obtained from the model, since it was the most realistic current product for this region as tested in Da-Allada et al. (2013), we used the near-surface velocity from satellite-tracked drifting buoy observations, available from a monthly mean climatology on a $1^{\circ} \times 1^{\circ}$ grid (Lumpkin and Garzoli, 2005).

\section{Results}


We focused on three separate regions characterized by large mixed-layer salinity variability (Figure 1d). The Northern Gulf of Guinea (NGoG; $2^{\circ} \mathrm{S}-5^{\circ} \mathrm{N}, 3^{\circ}-10^{\circ} \mathrm{E}$ ), where the Niger River flows into the Atlantic Ocean, and the Southern Gulf of Guinea (SGoG; $2^{\circ}-10^{\circ}$ S, $6^{\circ}-14^{\circ} \mathrm{E}$ ), where the Congo River meets the Atlantic Ocean, are regions where observed surface salinity variability is maximum. The Equatorial Gulf of Guinea region (EGoG, $3^{\circ} \mathrm{S}$ $1^{\circ} \mathrm{N}, 3^{\circ} \mathrm{W}-3^{\circ} \mathrm{E}$ ) encompasses the seasonal equatorial cold tongue (Jouanno et al., 2011), characterized by strong equatorial dynamics and large open-ocean SSS variability within the Gulf of Guinea.

\subsection{Model validation}

Modeled and observed SSS seasonal cycles were calculated for the period of the numerical experiment, from 1993-2009. The model reproduced the observed SSS annual mean and reasonably reproduced the spatial distribution of the amplitude of SSS seasonal and observations yielded a region of high salinity. Regions of SSS minima and large SSS variability were observed near the mouths of the Congo and Niger Rivers and in the $5^{\circ}-12^{\circ} \mathrm{N}$ latitude band corresponding to meridional displacement of the ITCZ (Figure 2b). However, as compared to observations, the model exhibited lower variability around the Niger River mouth and off the coast near $10^{\circ} \mathrm{N}, 15^{\circ} \mathrm{W}$. As suggested by Da-Allada et al. (2013), this result could be due to a lack of accuracy in model runoff forcing. The observed high coastal SSS variability is not necessarily associated with rivers and could be due to an amplification of the seasonal cycle of precipitation by nearby coastal mountains (e.g. Fouta-Djallon near $10^{\circ} \mathrm{N}$, $15^{\circ} \mathrm{W}$, or Mount Cameroon near $5^{\circ} \mathrm{N}, 10^{\circ} \mathrm{E}$, close to the Niger River mouth) that may not be captured by ERA-I products. 
211 During the same time period, 2006-2007, model salinity was also compared with in situ 212 salinity from a PIRATA buoy located at $0^{\circ} \mathrm{N}, 0^{\circ} \mathrm{E}$ (Bourlès et al., 2008). During this time 213 period, mooring-measured subsurface salinity was obtained at 1, 20, 40, and $120 \mathrm{~m}$. From the 214 surface to a depth of $25 \mathrm{~m}$, the model reproduced the amplitude and the phase of the seasonal 215 cycle for PIRATA salinity observations (Figure 3). The vertical structure of salinity was in 216 good agreement with PIRATA observations. The model was saltier from 25-100 m in depth, 217 possibly reflecting a salinity maximum linked to the equatorial undercurrent and hardly captured by the PIRATA mooring due to salinity sensor positions in the vertical.

By comparing Figures $4 \mathrm{a}$ and $\mathrm{b}$, it was determined that the model accurately reproduced 220 the magnitude and the direction of annual mean observed surface currents (Lumpkin and 221 Garzoli, 2005), namely the eastward Guinea Current (GC) along the northern coast of the Gulf of Guinea and the westward South Equatorial Current (SEC) with its two branches located on either side of the equator. However, for the eastern coastal region the comparison was not so convincing. The seasonal cycle of zonal currents (Figures 4c and 4d) was also correctly reproduced - the GC was determined to be at a maximum during the summer while the SEC indicated seasonal maxima during May-June and November-December.

For interannual variability, both the modeled and observed interannual standard deviation (ISTD) yielded areas of large variability near the mouths of rivers (Figure 5). However, the modeled ISTD displayed slightly lower variability (of approximately $0.2 \mathrm{psu}$ ) than that of the observed ISTD, particularly close to the mouths of rivers. The differences could be due to 231 model parameterization (a representation of precipitation or vertical mixing parameterization) or a lack of SSS observations for some regions. Overall agreement between modeled and observed SSS suggests that the model reasonably reproduced the dynamics of the region, and 
234 allowed us to investigate the mechanisms controlling SSS variations on seasonal and 235 interannual time scales.

236

237

238

239

240

241

242

243

\subsection{The seasonal mixed-layer salinity balance}

In this sub-section, we compare the seasonal cycles of SSS and the SSS tendency obtained from model and observations then use the model to examine various contributions to the SSS seasonal cycle.

In the NGoG, the model reasonably reproduced the seasonal evolution of observed SSS (Figure 6a). There is a two-month lag between modeled and observed SSS. The causes of this lag remain an open question. It can be due to forcing errors (large differences exist between different precipitation products) but could also result from dynamical issues. Simulated and observed SSS tendencies were in good agreement (Figure 6b) with a 0.87 correlation coefficient at the $99 \%$ significance level. The modeled salinity tendency was positive from December to August and negative from September to November. It reached a maximum during May, as for observations, and a minimum in November, lagging the observation minimum by one month. Since vertical diffusion was taken into account, as compared to DaAllada et al. (2013), the model improved the amplitude and the phase of the seasonal cycle.

The seasonal cycle of various contributions to salinity balance (Figure 6c) indicates that from January to September, vertical diffusion, total (horizontal + vertical) advection, and freshwater flux control the seasonal cycle of SSS. Due to the strong input of freshwater from precipitation (54\%) and rivers (46\%), the freshwater flux term was negative all year long. Interestingly, only vertical diffusion and vertical advection contributed to the salinization seen in the model and observations between January and August, whereas the contribution of meridional advection remained negative throughout the period and, therefore, tended to decrease SSS (with the exception of July-August when the term was slightly positive). In the 
model, vertical diffusion displayed its maximum during May-June (a period of strong cooling in the equatorial Atlantic), during the time of maximum observed and modeled tendencies. The significant contribution of vertical diffusion can be explained, as in the heat budget (Jouanno et al., 2011), by the strong vertical shear of horizontal velocity observed during this period (Figure 7) and the strong vertical velocities (Figure 7b) that bring salty waters in the mixed-layer. Note that at the same time, wind stress, dominated by meridional wind stress, increased. This strong vertical shear observed during May-June appeared when surface currents reached their maximum (Figures 7c). It is worth noting that $K z$ was at a maximum during August-September while maximum salinization occurred during May-June. The link between $\mathrm{Kz}$ (Figure 7e) and salinization is not straightforward. The vertical gradient of salinity within the upper thermocline was lower from June to September as compared to the rest of the year (Figure 7a), leading to a decrease in the turbulent salt flux even though $\mathrm{Kz}$ is still important. A high value for $\mathrm{Kz}$ during this period is likely the result of low stratification and static instabilities triggered by increased latent heat flux (Jouanno et al. 2011). The key 272 role played by vertical diffusion in the region confirms the assumption suggested in Da273 Allada et al. (2013), and was also noted by Berger et al. (2014). Due to a peak of upward vertical velocity at the depth of the mixed-layer and the presence of strong negative vertical salinity gradients, the vertical advection of salt also reached a maximum during May. Height (SSH) variability, as shown in Schouten et al. (2005). Schouten et al. (2005) indicated that SSH responds to basin scale dynamics, namely the propagation of equatorial Kelvin and Rossby waves due to changes in surface wind stress within the equatorial region. In particular, the intensification of trade winds during May to June drives Ekman divergence (not shown) 
and equatorial upwelling, generating equatorial waves and contributing to the formation of the seasonal cold tongue.

From October to December, although contributions of vertical advection and vertical diffusion remained positive, the SSS tendency decreased, explained by freshening peaks due to freshwater fluxes and zonal and meridional advection. Zonal advection has a maximum freshening effect during November, one month after Niger River peak flow (Dai et al., 2009), which is explained by SEC offshore transport of fresh coastal water.

In the EGoG, the model also correctly reproduced ( $r=0.91$ at the $99 \%$ significance level) the seasonal evolution of observed SSS (Figure 8a), although modeled SSS was slightly lower than that observed from December to May. The seasonal evolution of simulated and observed SSS tendencies was in relatively good agreement $(r=0.73$ at the $99 \%$ significance level; Figure 8b). The modeled salinity tendency reached a maximum in observations during May and a minimum in December, lagging the observation minimum by one month.

Seasonal evolution of mixed-layer salinity mainly resulted from a balance between the salinization effects of vertical diffusion and the freshening effect of zonal advection, with the 296 exception of September to October when these two terms were weak and freshwater flux 297 dominated the mixed-layer salinity balance (Figure 8c). Vertical diffusion displayed a strong 298 seasonal cycle with a maximum during May, leading to the peak rate for salinization seen 299 both in the model and observations, coinciding with formation of the cold tongue enhanced by 300 vertical mixing (Jouanno et al., 2011). The result is due to an increase in vertical shear 301 between surface currents and the Equatorial Undercurrent (EUC, Figure 9c) in response to the 302 westward strengthening of the SEC. As in the NGoG, Kz was at a maximum during August to 303 September (Figure 9e) while maximum salinization occurred during May to June when 304 vertical shear reached its maximum. Wind stress, dominated by meridional wind stress, 
increased from May-June (Figure 9d). Due to the strengthening of the SEC, zonal advection indicated a strong seasonal cycle with a maximum freshening effect during December, transporting eastern Gulf of Guinea freshwater. The term explains the surface freshening observed in the region at the end of the year. The contributions of vertical and meridional advection were at least three times weaker than the NGoG. During September-October, the contributions of various terms of salinity balance are weak (Figure 8c). The horizontal advection is slightly negative and tends to compensate the slightly positive vertical diffusion.

The freshwater flux, whose magnitude is slightly larger than vertical diffusion and horizontal advection, is dominated by evaporation in this period so this term is the main driver of the 314 increase in the mixed-layer observed salinity.

315 In the SGoG (Figure 10a), the modeled SSS was higher than the observed SSS from December to March with the strongest discrepancy occurring in January (with a maximum difference of 1 psu). During the rest of the year (April to November), model SSS was slightly lower (difference $<0.5 \mathrm{psu}$ ) than the observed SSS. Despite these discrepancies, the seasonal evolution of SSS was well reproduced by the model. In particular, the rate of salinization 320 reached an annual peak in May in both the model and observations (Figure 10b). In this region, SSS observations were very sparse and uncertainty in the observed SSS product was high (Da-Allada et al., 2013). Therefore, caution is required when comparing model results 323 and SSS observations.

324 The main salinity balance in this region (Figure 10c) occurred between the salinization 325 effects of vertical diffusion and vertical advection, and the freshening effects of horizontal 326 advection and freshwaters fluxes (mainly Congo River runoff, representing $80 \%$ of freshwater 327 inputs in this box). The contributions of the vertical advection and diffusion followed a semi328 annual cycle. The May peak for these two terms and a decrease in the horizontal advection 
explained the annual peak in salinity tendency. Instead, the November peak was balanced by the effect of horizontal advection leading to the twice weaker maximum salinity tendency during this period. The November peak for horizontal advection contribution was largely due to an increase in the zonal salinity gradient in response to an increase in Congo River 333 discharge during this period. Vertical advection and vertical diffusion were at a maximum during April to May when wind stress was at its maximum and northward (Figure 11d). Maximum vertical advection contributions occurred when vertical velocity was upward, with the vertical salinity gradient always negative (Figure $11 \mathrm{a}-\mathrm{b})$. Here, the semi-annual cycle in vertical velocity was largely due to remote forcing (Doi et al., 2007). Maximum vertical diffusion was due to the strong vertical shear observed when surface currents were at a maximum (Figure 11c). As for NGoG and EGoG, there is no obvious link between the strength of $\mathrm{Kz}$ (Figure 11e) and strength of the salinisation. The freshwater term was negative throughout the year and indicated a magnitude similar to in NGoG.

\subsection{Processes of SSS interannual variability from 1993-2009}

We now investigate the different processes controlling SSS on interannual time scales

344 within the same three regions. To obtain interannual anomalies, monthly seasonal climatology 345 was removed from all SSS tendency terms and then remaining high frequency variability was 346 removed using a 25-month Hanning Filter.

347 Hereafter, horizontal advection is referred to as ADH $=$ ADU + ADV (as ADU and ADV

348 defined in Eq.1), and vertical advection (ADW), vertical diffusion (DIFV), and entrainment 349 (ENT) are grouped together in a vertical process term referred to as VPR $=$ ADW + DIFV + 350 ENT. Finally, we define oceanic processes in Eq. 1 as OPR $=$ ADH + ADW + DIFL + DIFV $351+$ ENT and the freshwater flux term FWF. 
The interannual SSS anomalies spatially averaged in the boxes for the model and 353 observations are presented in Figure 12. Both of the time series displayed a similar evolution for NGoG and EGoG ( $r=0.70$ and $r=0.61$ at the $99 \%$ significance level, respectively). For the SGoG, since the observations were too scarce to provide an interannual time series, the observations are not shown. A significant SSS increase was observed in the NGoG during recent years: +0.5 psu from late 2002 to 2006. Da-Allada et al. (2014) closely investigated the cause of this SSS increase and determined that it was largely due to changes in atmospheric fluxes, more precisely a regional decrease in precipitation, while changes in evaporation were weak (Figure 13). The difference observed between observations and modeled results could 361 come from the forcing products that we used in this study (such as atmospheric forcing), and 362 also from the observations.

Different processes contributing to interannual variations in the mixed-layer salt budget

364 for the NGoG are presented in Figure 14. Contributions of the freshwater flux and oceanic 365 process terms display similar amplitude and oppose one another most of the time (Figure 366 14a). Therefore, both terms are important for explaining interannual anomalies within the 367 mixed-layer salt budget. To establish which oceanic processes dominate the mixed-layer 368 budget on interannual time scales, we separated the oceanic process terms into vertical 369 processes, horizontal advection, and horizontal diffusion (Figure 14b). Oceanic processes are 370 dominated by horizontal advection, vertical advection, and vertical diffusion (Figure 14c). We 371 concluded that interannual anomalies in the NGoG are largely driven by the precipitation, 372 vertical diffusion, and total advection terms.

373 For the EGoG, as for the NGoG, freshwater fluxes and oceanic processes are important 374 for the interannual salt budget (Figure 15a). In this region, the dominant oceanic phenomena 375 are horizontal advection and vertical processes (Figure 15b). Vertical processes are dominated 
by vertical diffusion and vertical advection (Figure 15c). We concluded that freshwater flux, total (horizontal + vertical) advection, and vertical diffusion explain most SSS interannual anomalies within the EGoG.

For the SGoG, as compared to the NGoG and EGoG, the freshwater flux term provides weaker interannual variability (Figure 16). Oceanic processes were well correlated $(r=0.76$, significant at the 99\% level) with the interannual anomaly tendency term and, therefore, largely drive interannual anomalies within the mixed-layer salt budget (Figure 16a). As for the NGoG and EGoG, horizontal advection and vertical processes dominated oceanic process terms (Figure 16b). The decomposition of vertical processes indicated that vertical processes are mainly due to vertical advection and vertical diffusion (Figure 16c). Our conclusion is that within the Southern Gulf of Guinea region, interannual SSS anomalies are driven by total advection and vertical diffusion.

To better evaluate the respective role of freshwater flux and winds on SSS interannual variability, in addition to the reference simulation (REF), two other runs were performed one, PCLIM, where ERA interim interannual precipitation is replaced by monthly 391 climatological precipitation computed from the same product and another, VCLIM, where ERA interim interannual winds are replaced by monthly climatological winds computed from the same product. For the NGoG region (Figure 17a), VCLIM compared better with REF than PCLIM regarding SSS anomalies $(r=0.94$ and $r=0.90$ at the $99 \%$ significance level with rms difference of 0.08 psu and 0.11 psu, respectively), particularly during the 2002-2009 period (r $396=0.98$ and $r=0.94$ at the $99 \%$ significance level with rms difference of 0.11 and 0.05 psu, respectively). This result indicates that interannual SSS variability in this region is largely driven by precipitation, as noted in Da-Allada et al (2014) for the later period, although wind 
SSS anomalies were well correlated with the REF time series $(r=0.94$ and $r=0.93$ at the 99\% significance level with rms difference of 0.04 and 0.05 psu, respectively) indicating that, in this region, changes in winds and precipitation are both important for understanding interannual SSS variability. In contrast, for the SGOG region (Figure 17c), since PCLIM compared much better with REF than VCLIM regarding SSS anomalies $(r=0.97$ and $r=0.59$ at the $99 \%$ and $98 \%$ significance level with rms difference of 0.05 and 0.14 psu, respectively), SSS interannual variability are largely due to changes in wind. This result is consistent with the dominant role of ocean processes (largely wind-driven) as identified in the salt budget above.

\section{Discussion and Conclusion}

In this study, we investigated the mechanisms that drive sea surface salinity (SSS) variability on seasonal and interannual time scales in the Gulf of Guinea, using a regional model simulation and SSS observations from 1993-2009. The model compared well with observations. We focused our study on the following regions of the Gulf of Guinea: 1) the Northern Gulf of Guinea (NGoG) where the Niger River flows into the Atlantic Ocean, 2) the Equatorial region of the Gulf of Guinea (EGoG), and 3) the Southern Gulf of Guinea region (SGoG) where the Congo River flows into the Atlantic Ocean.

For seasonal time scales, we determined that within the NGoG, mixed-layer salinity is dominated by vertical diffusion, freshwater flux, and total (horizontal + vertical) advection. For the EGoG, the seasonal evolution of mixed-layer salinity is largely due to vertical diffusion and zonal advection with the exception of September to October when freshwater fluxes, dominated by evaporation, drive the salinity balance. We determined that during the period of strong cooling within the equatorial Atlantic (May to June), vertical diffusion strongly contributes to the salt budget, similar to the heat budget (Jouanno et al., 2011). As 
suggested by Da-Allada et al. (2013) and in agreement with Berger et al (2014), vertical diffusion is important for determining the correct salinity balance for these regions. For the SGoG, the seasonal cycle of mixed-layer salinity is mainly a balance between the positive contributions of vertical advection and vertical diffusion, and negative contributions of horizontal advection and freshwater fluxes. The key role played by vertical advection in the salt budget of this region is in agreement with the result of a mixed-layer salinity model (DaAllada et al., 2013) and a similar OGCM (Berger et al., 2014).

Using an OGCM, we concluded that taking into account vertical diffusion improves the comparison with observations in terms of amplitude and phase for both near surface salinity and its variation, as compared to Da-Allada et al. (2013). Surprisingly, our results exhibited better agreement with observations than the study of Berger et al. (2014) for the easternmost portion of the Gulf of Guinea, although the two models were similar but with different experimental configurations. Berger et al. (2014) underestimated SSS by up to 2 psu and the SSS seasonal cycle had a two-month lag with climatology. Differences between the two model experiments are numerous. Berger et al. (2014) used a higher grid resolution, different surface forcing, and different reference climatology. The reasons for differing model skill should be investigated.

For interannual time scales, we determined that for the NGoG, SSS anomalies are first driven by precipitation then by wind-forced ocean dynamics. In particular, due to a significant decrease in precipitation (Da-Allada et al., 2014), we observed a SSS increase for recent years (2002-2009) in the NGoG. For the EGoG, changes in winds and freshwater flux are both important for explaining SSS interannual anomalies in this region. For the SGoG, only changes in wind could explain the interannual variability of the SSS. Contrary to the other 
two regions (the NGoG and EGoG), the freshwater flux was not found to play a key role in 448 the salinity balance on interannual time scales.

449 The reason for the weak freshwater flux effect in the SGoG, compared to the NGoG and 450 EGoG, is related to the displacement of the ITCZ. In this study, we used only climatology 451 runoff and we found that changes in freshwater flux are mainly due to changes in 452 precipitation as evaporation changes are weak. The NGoG and EGoG are under the influence of the ITCZ, contrary to the SGoG. For this reason, the freshwater flux term is smaller in the SGoG than the other two regions. This is consistent with Mignot et al (2003) who showed that the standard deviation of the anomalous freshwater flux is much smaller in the southern than the northern Gulf of Guinea.

The interannual SSS anomalies presented in the Figure12a-b roughly showed a similar evolution in model and observations, but also differences. For example, in the NGoG, both observations and model results showed a SSS increase over the period 2003-2006 but with larger amplitude in the model ( $>0.7 \mathrm{psu}$ ) than in the observations (about $0.4 \mathrm{psu}$ ). As we 461 found above that precipitation plays an important role in SSS anomalies and rainfall products 462 are subject to uncertainties, it is possible that this difference could come from a bias in the 463 rainfall product we used. Indeed, Da-Allada et al (2014) showed that the decrease in precipitation in the North of Gulf of Guinea, responsible for the SSS increase here, is more pronounced in ERA interim than in the GPCP (Global Precipitation Climatology Project) product (Alder et al., 2003). The differences between modelled and observed SSS interannual anomalies could also come from the observations, which are relatively scarce in the Gulf of Guinea where, moreover, SSS Argo data remain questionable due to the thin mixed layers associated with river runoff and strong precipitation. 
In the NGoG and EGoG, the important contribution of precipitation and oceanic processes

471 to the interannual salinity tendency are of the same order and generally opposite in sign. In

472 the SGoG, there is less symmetry and the interannual variability of salinity tendency is larger

473 than in the NGoG and EGoG, especially in the years with strong wind anomalies (e.g. 1994,

4741997 and 2006-2007). This is consistent with our test simulations that showed that interannual

475 SSS anomalies in the SGoG are mostly under the influence of winds. We also found that, as

476 in the seasonal cycle, vertical diffusion plays an important role in the SSS interannual

477 anomalies, according to the model. This term represents processes at high frequencies or on

478 small vertical scales that are not explicitly solved by the model, and poorly observed.

479 Therefore it would be interesting to re-visit the conclusions found here with the model when 480 the observations will permit in the future.

481 In summary, atmospheric fluxes are important on interannual time scales in the northern

and equatorial regions of the Gulf of Guinea and associated with oceanic processes (vertical diffusion and total advection). In the southern region near the Congo River where oceanic processes largely control interannual variability this is not the case. While these oceanic processes are largely wind-driven, we investigated the role of local wind forcing but did not establish a clear relationship between changes in local wind forcing, wind stress curls, and surface current anomalies. We hypothesize that remote wind forcing changes could impact the easternmost portion of the Gulf of Guinea on interannual time scales, as for seasonal time 489 scales (Schouten et al., 2005; Doi et al., 2007). Changes in atmospheric forcing should be 490 investigated at the Atlantic Ocean basin scale.

491 This study reveals that the main terms which dominate the salinity balance in the 492 interannual variability are the same as those for the seasonal variability except for SGoG 493 region where the freshwater fluxes are no longer important at interannual timescales. The 
494

495

496

497

498

499

500

501

502

503

504

505

506

507

508

509

510

511

512

513

514

515

516

results of this study show the complexity of the seasonal and interannual mixed-layer salinity balance in the Gulf of Guinea.

\section{Appendix: Error Estimates}

To estimate the error bars on modeled and observed mixed-layer salinity tendency on a seasonal time scale, we first estimated SSS monthly errors ( $\left.e_{S}\right)$ as the standard error of all available SSS data during the 1993 to 2009 study period. Then, errors in mixed-layer salinity tendency ( ${ }^{e}$ ) were estimated using the Foltz and McPhaden (2008) formula, as follows: $e=\left(\sqrt{e_{S_{t+1}}^{2}+e_{S_{t-1}}^{2}}\right) / D t$, with $D t=2$ months.

\section{Acknowledgments}

SSS observations were obtained from the French SSS observation service and are available at http://www.legos.obs-mip.fr/observations/sss. We thank the CICESE for supercomputing facilities. We also thank the PIRATA Project and the TAO Project Office at NOAA/PMEL for providing open access to PIRATA data. The regional configuration was established in cooperation with the DRAKKAR project (http://www.drakkar-ocean.eu/). Special thanks are due to Fabien Durand and Elodie Kestenare for interesting discussions. C.Y. D-A thanks the SCAC of the French Embassy in Cotonou, Bénin and the IRD for support through PhD grants. The research leading to these results received funding from the EU FP7/2007-2013 under grant agreement no. 603521. The authors thank TOTAL S.A. for supporting ICMPA, where this work was completed. Finally, sincere thanks are due to reviewers, whose precious contributions helped improve and complete an earlier version of this manuscript. 


\section{References}

Adler RF, et al. (2003), The Version 2 Global Precipitation Climatology Project (GPCP) monthly precipitation analysis (1979-present), J. Hydrometeorol.,4, 1147- 1167.

Barnier B, Madec G, Penduff T, Molines JM, Tréguier AM, Beckmann A, Biastoch A, Boning C, Dengg J, Gulev S, Le Sommer J, Rémy E, Talandier C, Theetteen S, Maltrud M, Mc Lean J (2006) Impact of partial steps and momentum advection schemes in a global ocean circulation model at eddy permitting resolution. Ocean Dyn., 56(5-6), 543567.

Berger H, Tréguier AM, Perenne N, Talandier C (2014) Dynamical contribution to sea surface salinity variations in the eastern Gulf of Guinea based on numerical modelling. Accepted to Clim. Dyn.

Blanke B, Delecluse P (1993) Variability of the tropical Atlantic Ocean simulated by a general circulation model with two different mixed-layer physics. J. Phys. Oceanogr., 23, 1363-1388.

Bourlès B, Lumpkin R, McPhaden MJ, Hernandez F, Nobre P, Campos E, Yu L, Planton S, Busalacchi A, Moura AD, Servain J, Trotte J (2008) The PIRATA program: History, accomplishments and future directions. Bull. Am. Meteorol. Soc., 89, 1111-1125.

Bretherton FP, Davis RE, Fandry CB (1976) A technique for objective mapping and design of oceanographic experiments. Deep Sea Res., 23, 559-582.

Da-Allada YC, Alory G, du Penhoat Y, Kestenare E, Durand F, Hounkonnou NM (2013) Seasonal mixed-layer salinity balance in the Tropical Atlantic Ocean: Mean state and seasonal cycle. J. Geophys. Res. Oceans, 118, doi: 10.1029/2012JC008357. 
540 Da-Allada YC, Alory G, du Penhoat Y, Jouanno J, Hounkonnou NM (2014) Causes for the 541 Recent Increase in Sea Surface Salinity in the Gulf of Guinea. In press in African $542 \quad$ Journal of Marine Science.

543 Dai A, Trenberth K (2002) Estimates of freshwater discharge from continents: latitudinal and seasonal variations. J. Hydrometeorology, 3, 660-687.

545 Dai A, Qian T, Trenberth K, and Milliman J (2009) Changes in continental freshwater discharge from 1948 to 2004. J. Clim., 22:2773-2792.

de Boyer Montégut C, Madec G, Fischer AS, Lazar A, Ludicone D (2004) Mixed-layer depth over the global ocean: An examination of profile data and a profile-based climatology. J. Geophys. Res. Oceans, 109 (C12), 52-71.

Dessier A, Donguy JR (1994) The sea surface salinity in the tropical Atlantic between $10^{\circ} \mathrm{S}$ and $30^{\circ} \mathrm{N}-$ seasonal and interannual variations (1977- 1989). Deep Sea Res., Part I, 41, $81-100$.

Doi T, Tozuka T, Sasaki H, Masumoto Y, Yamagata T (2007) Seasonal and interannual variations of oceanic conditions in the Angola Dome. J. Phys. Oceanogr., DOI: 10.1175/2007JPO3552.1.

Ferry N, Reverdin G (2004) Sea surface salinity interannual variability in the western tropical Atlantic: An Ocean general circulation model study. J. Geophys. Res. Oceans 109, DOI 10.1029/2003JC002122

Foltz GR, Grodsky SA, Carton JA, McPhaden MJ (2004) Seasonal salt budget of the northwestern tropical Atlantic Ocean along $38^{\circ}$ W. J. Geophys. Res., 109, C03052, doi: 10.1029/2003JC002111.

Foltz GR, McPhaden MJ (2008) Seasonal mixed layer salinity balance of the tropical North Atlantic Ocean. J. Geophys. Res., 113, C02013, doi: 10.1029/2007JC004178. 
Jouanno J, Marin F, du Penhoat Y, Sheinbaum J, Molines JM (2011) Seasonal heat balance in the upper $100 \mathrm{~m}$ of the equatorial Atlantic Ocean. J. Geophys. Res., 116, C09003, doi: 10.1029/2010JC006912.

Jouanno J, Marin F, du Penhoat Y, Sheinbaum J, Molines JM (2013) Intraseasonal modulation of the surface cooling in the Gulf of Guinea. J. Phys. Oceanogr., doi:10.1175/JPO-D-12-053.1.

Large W, Yeager S (2004) Diurnal to decadal global forcing for ocean sea ice models: The data sets and flux climatologies. Rep. NCAR/TN-460+STR, Natl. Cent. for Atmos. Res., Boulder, Colorado.

Lumpkin R, Garzoli SL (2005) Near-surface circulation in the tropical Atlantic. Deep Sea Res., Part I, 52, 495- 518.

Lukas R, Lindstrom E (1991) The mixed layer of the western equatorial Pacific Ocean. J. Geophys. Res., 96, suppl., 3343-3357.

Madec G (2008) «NEMO ocean engine ». Note du pole de modélisation, Institut PierreSimon Laplace (IPSL), Paris.

Materia S, Gualdi S, Navarra A, Terray L (2012) The effect of Congo River freshwater discharge on Eastern Equatorial Atlantic climate variability, Clim. Dyn., Doi: 10. 1007/s00382-012-1514-X.

Mignot J, Frankignoul C (2003) On the interannual variability of surface salinity in the Atlantic, Clim. Dyn., Doi: 10. 1007/s00382-002-0294-0

Peter AC, Le Hénaff M, du Penhoat Y, Menkes CE, Marin F, Vialard J, Caniaux G, Lazar A, (2006) A model study of the seasonal mixed-layer heat budget in the equatorial Atlantic. J. Geophys. Res., 111, C06014, doi:10.1029/2005JC003157. 
Reverdin, G., E. Kestenare, C. Frankignoul, and T. Delcroix (2007) Surface salinity in the Atlantic Ocean $\quad\left(30^{\circ} \mathrm{S}-50^{\circ} \mathrm{N}\right) . \quad$ Prog. Oceanogr., $73,311-340$, doi:10.1016/j.pocean.2006.11.004.

590

591

592

593

594

595

596

597

598

599

600

601

602

603

604

605

606

607

608

609

610

Schouten, MW., RP. Matanao, and TP. Strub (2005) A description of the seasonal cycle of the equatorial Atlantic from altimeter data, Deep-sea Research I 52 (2005) 477493...doi:10.1016/j.dsr.2004.10.007.

Sprintall J, Tomczak M (1992) Evidence of the barrier layer in the surface layer of the tropics. J. Geophys. Res., 97, 7305- 7316.

Tzortzi E, Josey SA, Skrokosz M, Gommenginger C (2013) Tropical Atlantic salinity variability: new insights from SMOS. Accepted to Geophys. Res. Lett. Doi:10.1002/grl.50225

Vialard J, Menkes C, Boulanger JP, Delecluse P, Guilyardi E (2001) A model study of oceanic mechanisms affecting equatorial Pacific sea surface temperature during the 1997-1998. EL Nino. J. Phys. Oceanogr., 31 1649-1675.

Yu L (2011) A global relationship between the ocean water cycle and near surface salinity. J. Geophys. Res., 116, C10025, doi: 10.1029/2010JC006937

Webster PJ (1994) The role of hydrological processes in ocean atmosphere interactions. Rev. Geophys., 32, 427-476. 
612 Figure 1. SSS annual mean and standard deviation from the model ((a) and (b)), and

613 observations ((c) and (d)) calculated from monthly averaged values spanning the 1993-2009

614 period. The position of the two major rivers (the Niger and Congo) are indicated in (a). Sub-

615 regions used in the study are marked in (d).

616

617 Figure 2. Annual mean for ERA Interim (a) evaporation and (b) precipitation. The units are

618 mm.day ${ }^{-1}$.

619

Figure 3. Seasonal salinity profile at $\left(0^{\circ} \mathrm{N}, 0^{\circ} \mathrm{E}\right)$ from the PIRATA mooring (a) and the model

(b). Model and PIRATA salinity at the equator were obtained for the 2006-2007 period.

623

Figure 4. Surface current annual mean: (a) for the model and (b) for DRIFTER products, with units of $\mathrm{m} . \mathrm{s}^{-1}$. Latitude - time (month) seasonal surface currents $\left(5^{\circ} \mathrm{W}-5^{\circ} \mathrm{E}\right.$ average) (c) for the model and (d) for DRIFTER. The units are $m \cdot \mathrm{s}^{-1}$.

627

Figure 5. Interannual standard deviation of SSS (a) from the model and (b) from observations computed for 1993-2009. The units are psu.

630

631 Figure 6. SSS budget for the NGoG region: a) Seasonal cycle of SSS from observations (in black) and from the model (in red). b) Salinity tendency terms for the mixed-layer for observations and for the model. Shaded areas indicate error estimates (see Appendix A) for these terms. c) Individual contributions to the salt balance equation for zonal advection (ADU 
635 in blue), meridional advection (ADV in dashed blue), vertical advection (ADW in green), 636 freshwater flux (FWF in pink), vertical diffusion (DIFV in red), horizontal diffusion (DIFL in 637 dashed light blue), and entrainment (ENT in dashed green). The units are psu for a) and 638 psu.month ${ }^{-1}$ for b) and c).

639

640 Figure 7. Seasonal evolution of vertical profiles for the NGoG region. a) Salinity (psu) and 641 vertical salinity gradient (dashed contours in psu.m ${ }^{-1}$ ). Contour intervals are 0.1 psu.m ${ }^{-1}$. b) 642 Vertical velocity $\left(\mathrm{m} . \mathrm{s}^{-1}\right)$. c) Horizontal current speed $\left(\mathrm{m} . \mathrm{s}^{-1}\right)$ with square of vertical shear 643 (dashed contour in $\mathrm{s}^{-2}$ ). Contour intervals are $0.15 \mathrm{~s}^{-2}$. d) Wind stress (red is total, black is 644 zonal, blue is meridional; N.m $\left.{ }^{-2}\right)$. e) Vertical diffusion coefficient $\left(\mathrm{m}^{-2} \cdot \mathrm{s}^{-1}\right)$. Thick black lines 645 indicate mixed-layer depths in a), b), c), and e).

646

647 Figure 8. Same as Figure 6 but for the EGoG region.

648

649 Figure 9. Same as Figure 7 but for the EGoG region.

650

651 Figure 10. Same as Figure 6 but for the SGoG region.

652

653

Figure 11. Same as Figure 7 but for the SGoG region.

654

655 Figure 12. Time series of SSS interannual monthly anomalies for the observations (black) 656 and the model (red). Time series were averaged over the study boxes (NGoG, EGoG, and 657 SGoG). The mean seasonal cycle was removed and a one-year running mean was applied (due 658 to a deficiency in data for several locations). The units are psu. 
660 Figure 13. Interannual anomalies for 1993-2009 within the three study boxes: (a) for 661 precipitation and (b) for evaporation.

662

663 Figure 14. Interannual anomalies for 1993-2009 for the mixed-layer salinity balance in the 664 Northern Gulf of Guinea (NGoG) region: a) salinity tendency (red), freshwater flux (FWF, 665 pink), oceanic processes (OPR, black); b) Decomposition of oceanic processes: oceanic 666 processes (black, same as the black line in the panel (a)), vertical processes (VPR, dashed 667 pink), horizontal advection (ADH, dashed blue), and horizontal diffusion (DIFL, dashed light 668 blue); c) Decomposition of vertical processes: vertical processes (dashed pink, same as the 669 dashed pink line in the panel (b)), vertical advection (ADW, green), vertical diffusion (DIFV, 670 dashed red), and entrainment (ENT, dashed green). For all of the terms, the mean seasonal 671 cycle was removed and a 25-month Hanning Filter was applied. All terms are in psu.year ${ }^{-1}$.

672 Figure 15. Same as Figure 14 but for the EGoG region.

673

674 Figure 16. Same as Figure 14 but for the SGoG region.

675

676 Figure 17. Time series of SSS interannual monthly anomalies for the reference simulation 677 (REF, red), the simulation with climatology precipitation (P CLIM, pink), and the simulation 678 with climatology winds (V CLIM, blue). Time series were averaged over the three study 679 boxes (NGoG, EGoG, and SGoG). The seasonal cycle was removed and a 25-month Hanning 680 Filter was applied. The units are psu. 
681

682

683

684

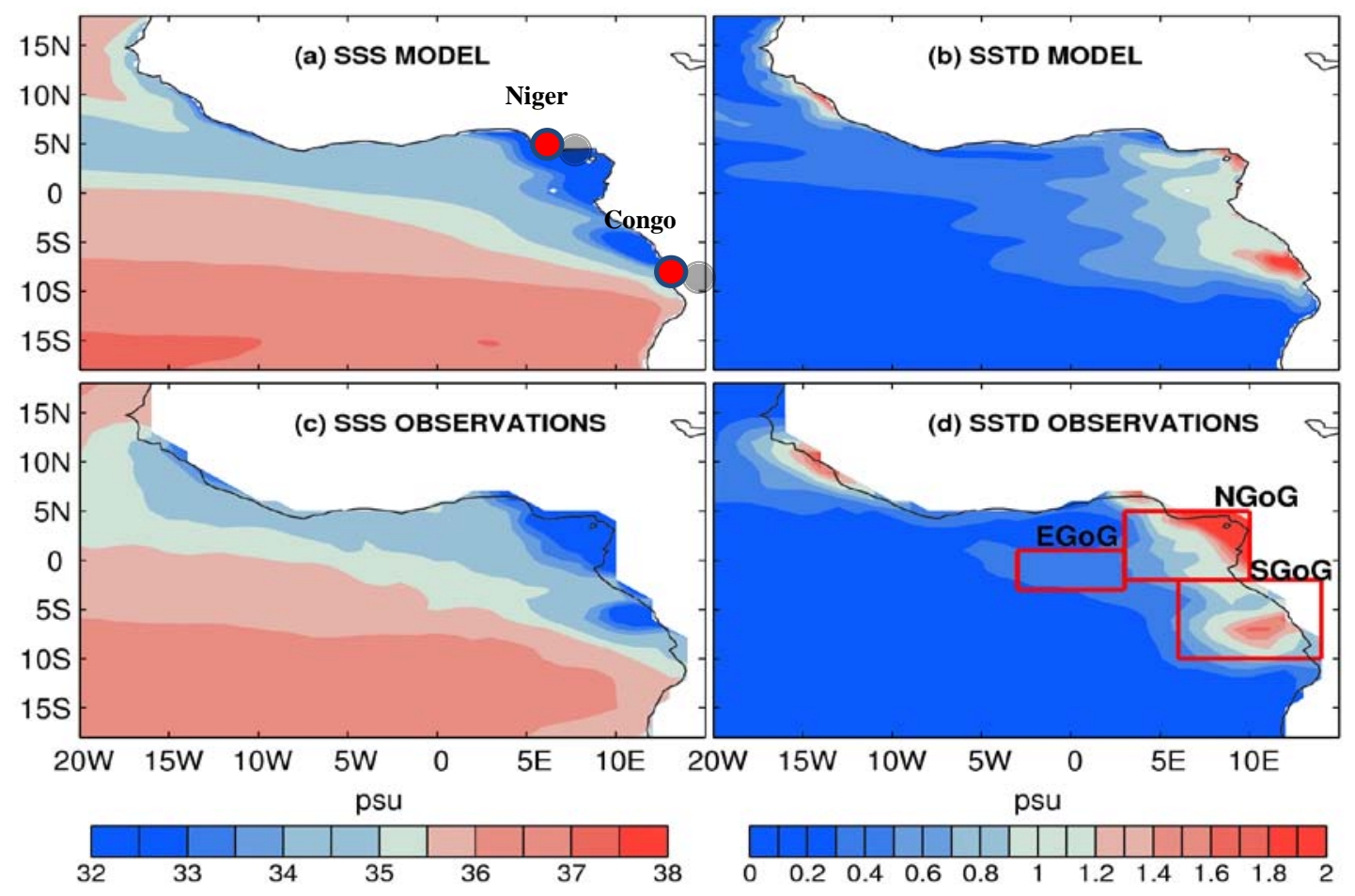

685 Figure 1. SSS annual mean and standard deviation from the model ((a) and (b)), and

686 observations ((c) and (d)) calculated from monthly averaged values spanning the 1993-2009

687 period. The positions of the two major rivers (the Niger and Congo) are indicated in (a). Sub-

688 regions used in the study are marked in (d). 
689

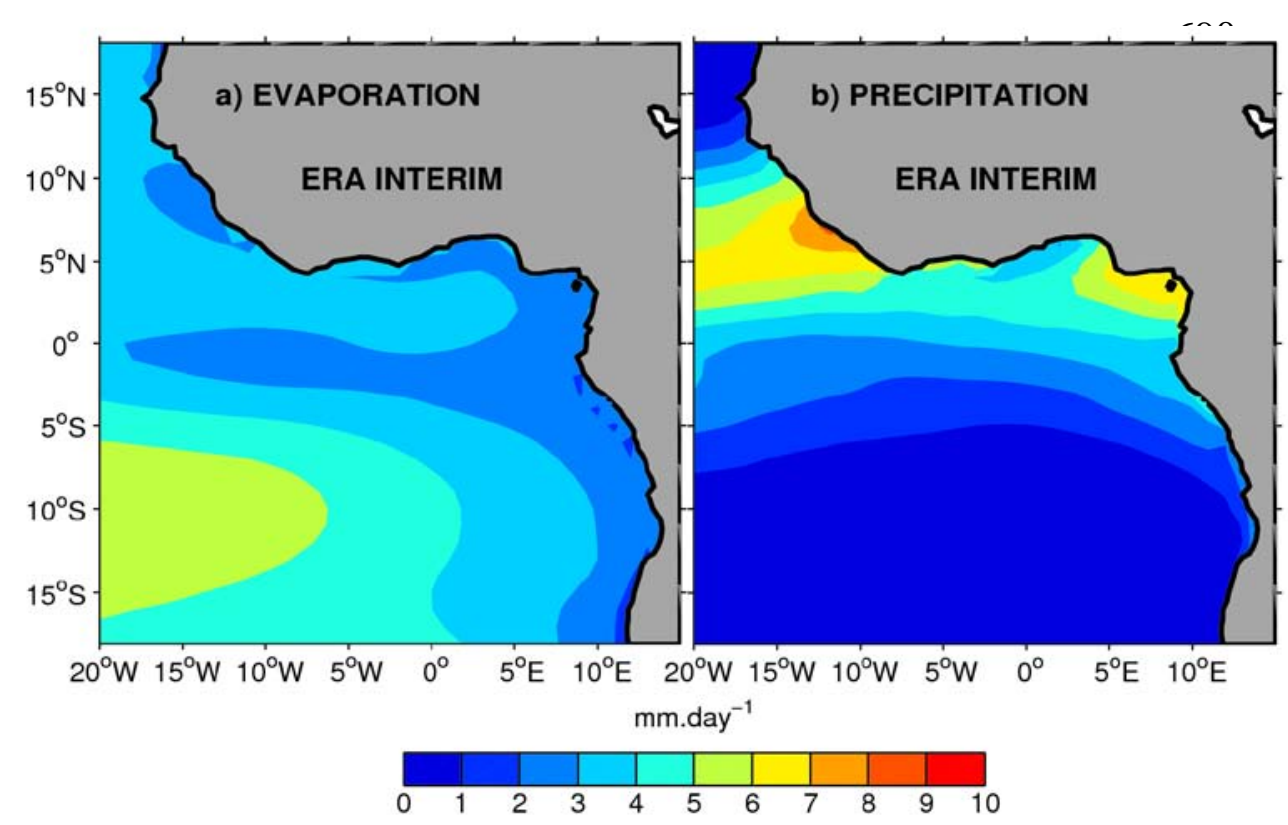

699

700

701 Figure 2. Annual mean for ERA Interim (a) evaporation and (b) precipitation. The units are 702 mm.day ${ }^{-1}$.

703

704

705

706

707

708

709

710

711

712 


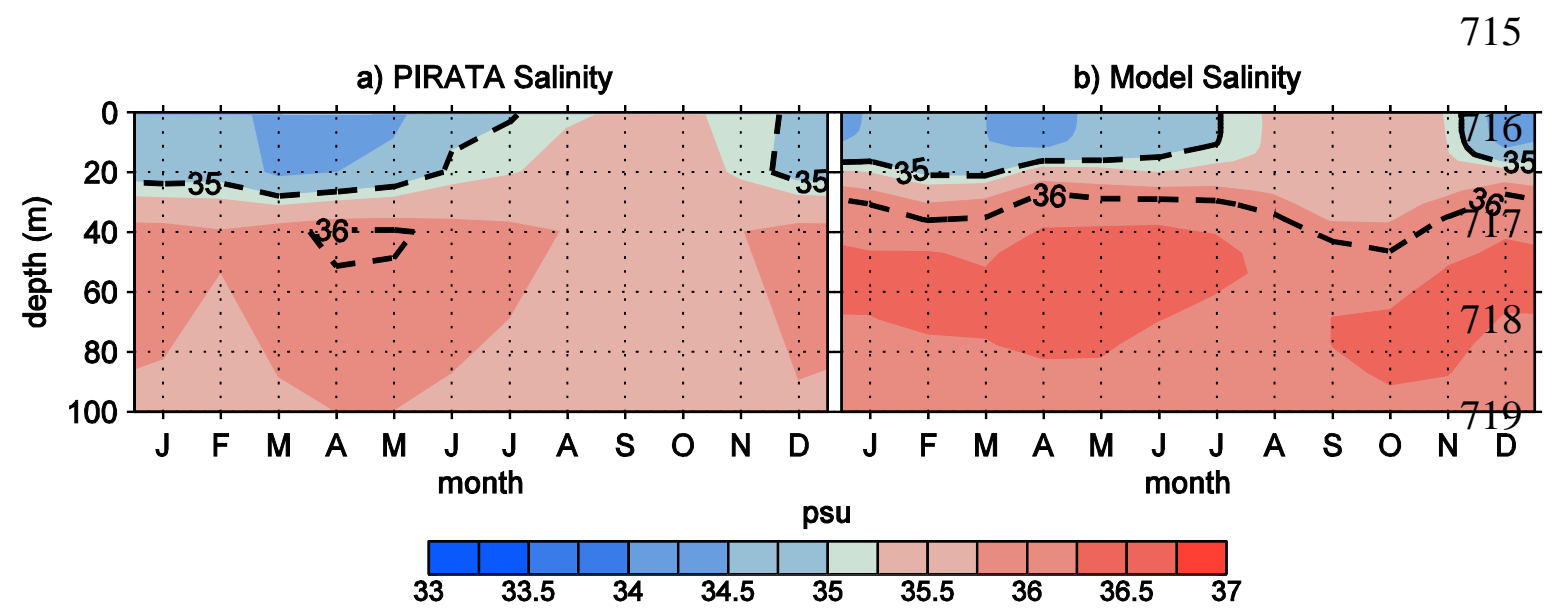

720 Figure 3. Seasonal salinity profile at $\left(0^{\circ} \mathrm{N}, 0^{\circ} \mathrm{E}\right)$ from the PIRATA mooring (a) and the model

721 (b). Model and PIRATA salinity at the equator were obtained for the 2006-2007 period.

722 Dashed lines represent the 35 and 36 psu isohalines. The units are psu.

723

724

725

726

727

728

729

730

731

732

733

734

735 


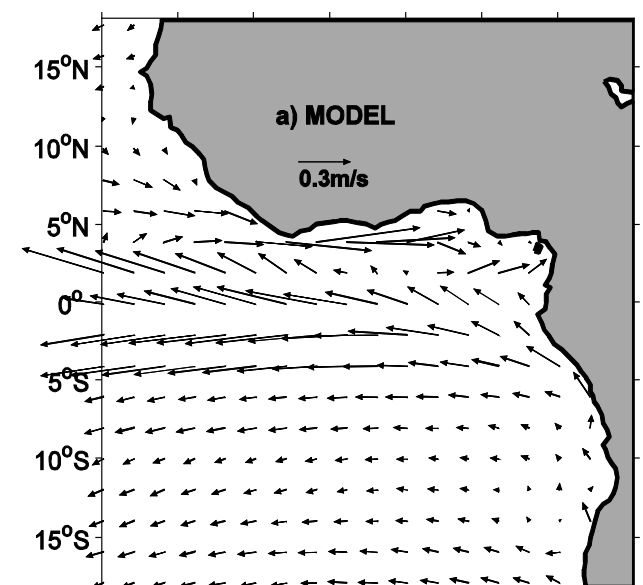

$20^{\circ} \mathrm{W} 15^{\circ} \mathrm{W} 10^{\circ} \mathrm{W} 5^{\circ} \mathrm{W} \quad 0^{\circ} 5^{\circ} \mathrm{E} \quad 10^{\circ} \mathrm{E}$

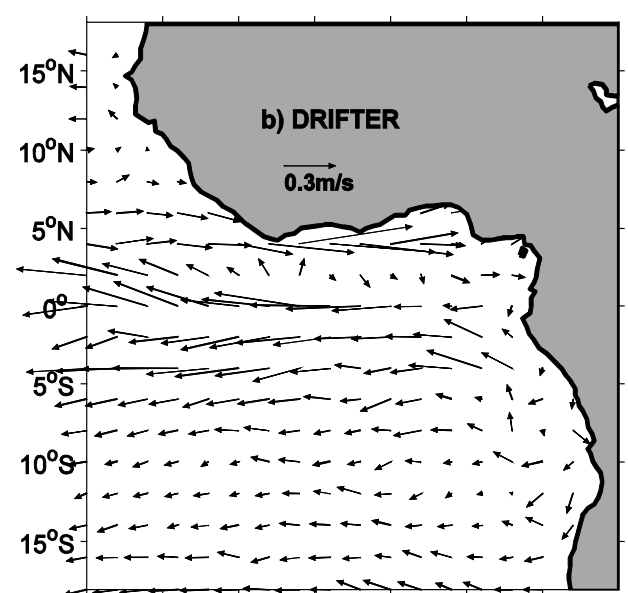

$20^{\circ} \mathrm{W} 15^{\circ} \mathrm{W} 10^{\circ} \mathrm{W} 5^{\circ} \mathrm{W} \quad 0^{\circ} \quad 5^{\circ} \mathrm{E} \quad 10^{\circ} \mathrm{E}$

743

744

745

746

747

748

749

750

751

752

c) U MODEL

d) U DRIFTER

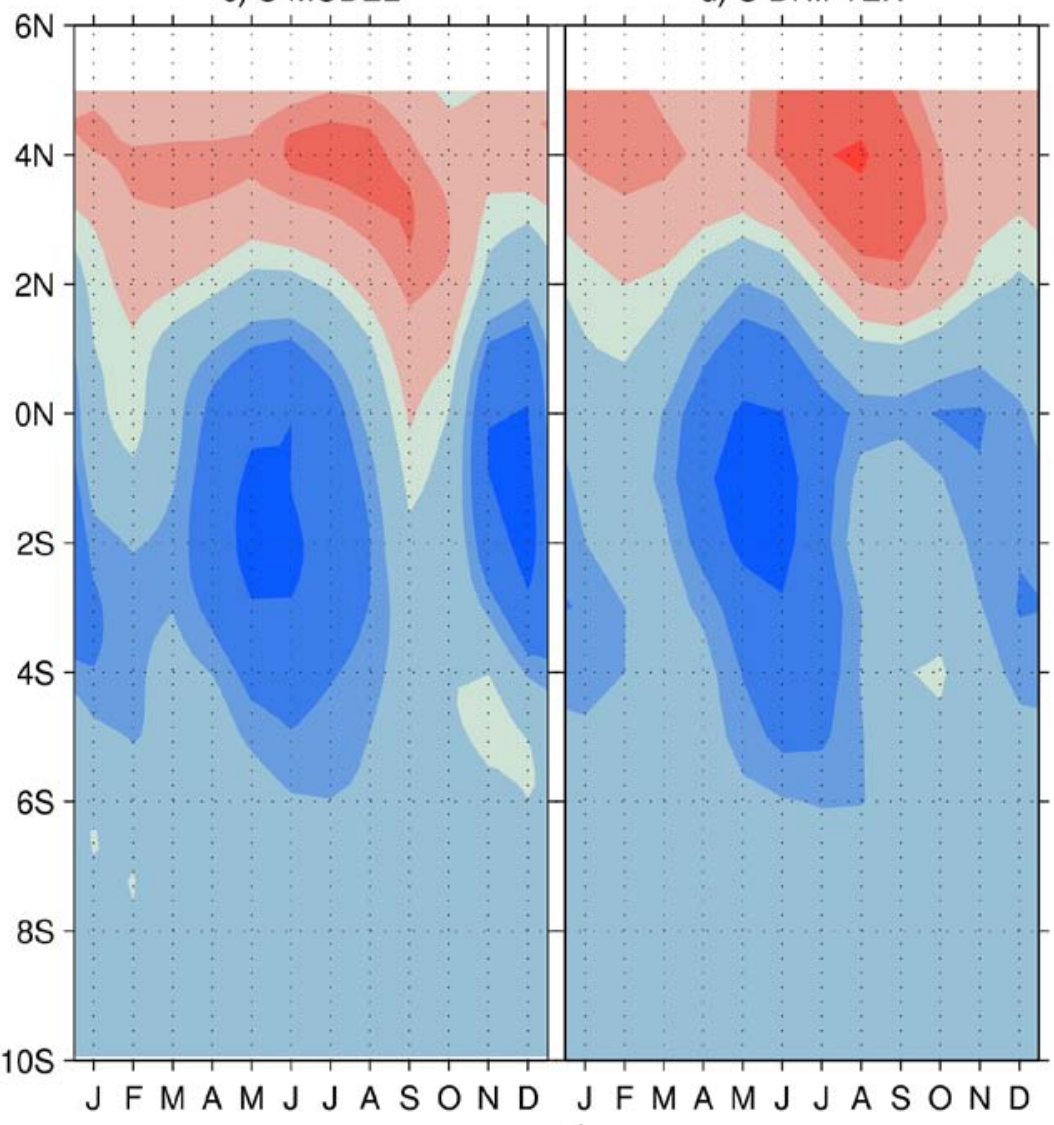

$\mathrm{m} \cdot \mathrm{s}^{-1}$

756

$\begin{array}{lllllllllll} & 0.7-0.6-0.5-0.4-0.3-0.2-0.1 & 0 & 0.1 & 0.2 & 0.3 & 0.4 & 0.5 & 0.6 & 0.7\end{array}$

757 
758 Figure 4. Surface current annual mean: (a) for the model and (b) for DRIFTER products, with 759 units of $\mathrm{m} . \mathrm{s}^{-1}$. Latitude - time (month) seasonal surface currents ( $5^{\circ} \mathrm{W}-5^{\circ} \mathrm{E}$ average) (c) for the 760 model and (d) for DRIFTER. The units are $m \cdot s^{-1}$.

761

762

763

764

765

766

767

768

769

770

771

772

773

774

775

776

777

778

779

780

781 


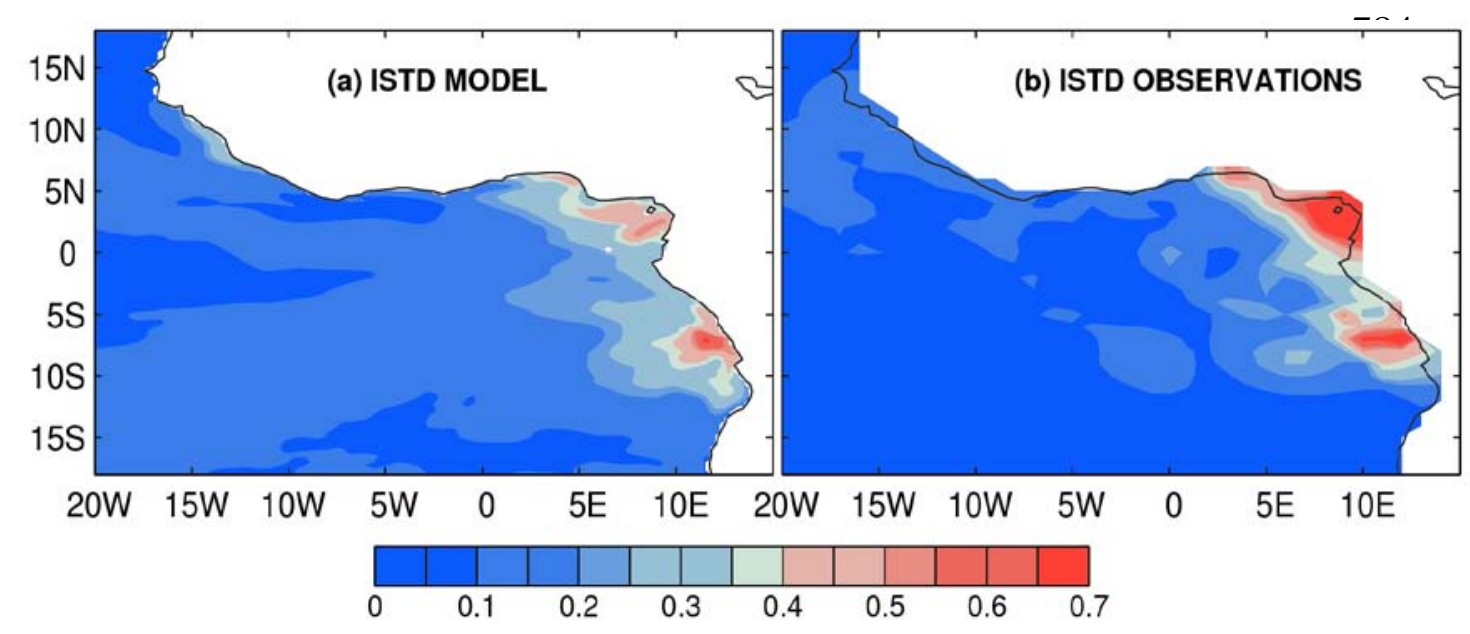

791

792

793 Figure 5. Interannual standard deviation of SSS (a) from the model and (b) from observations 794 computed for 1993-2009. The units are psu.

795 

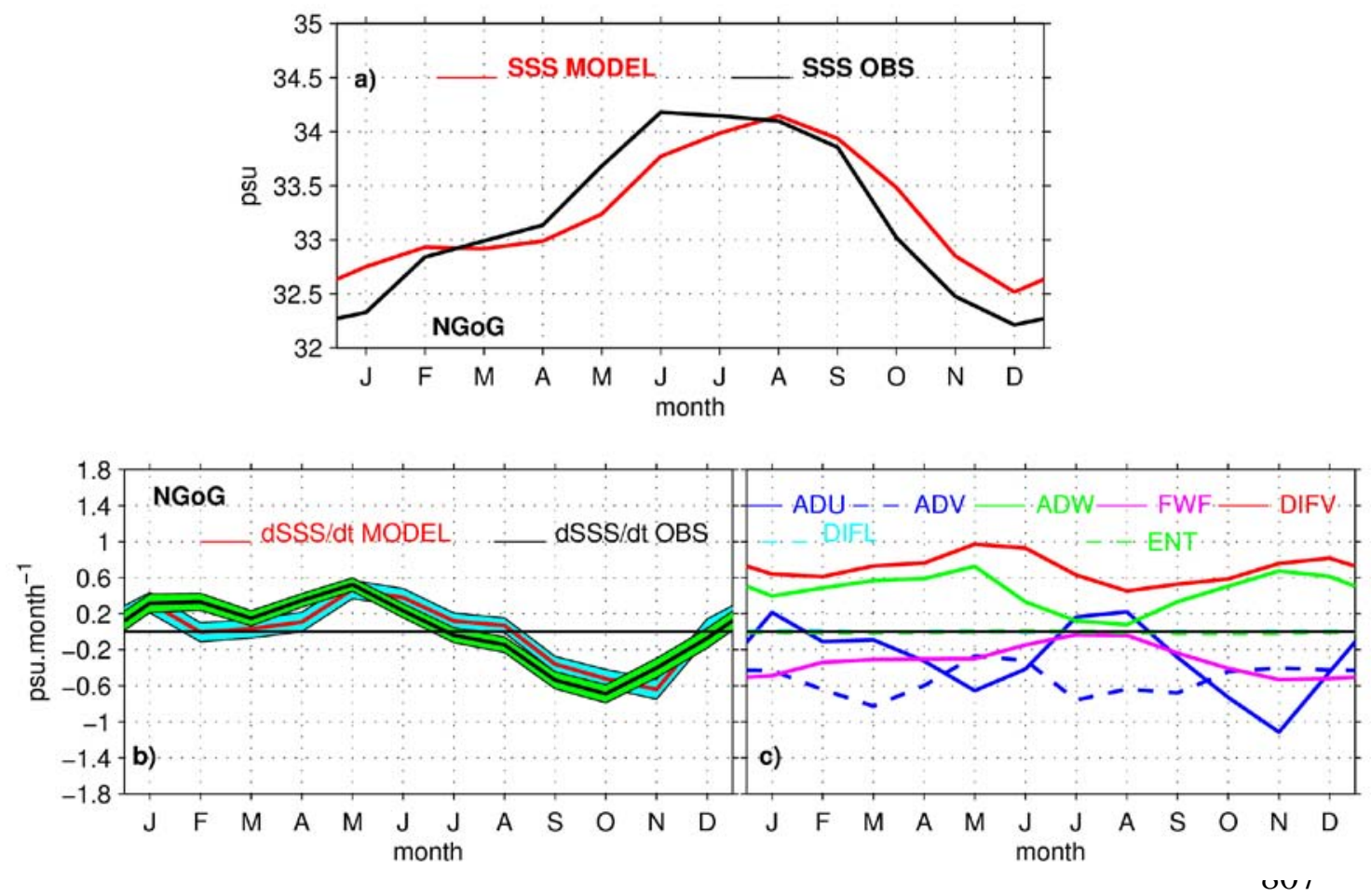

808 Figure 6. SSS budget for the NGoG region: a) Seasonal cycle of SSS from observations (in 809 black) and from the model (in red). b) Salinity tendency terms for the mixed-layer for 810 observations and for the model. Shaded areas indicate error estimates (see Appendix A) for 811 these terms. c) Individual contributions to the salt balance equation for zonal advection (ADU 812 in blue), meridional advection (ADV in dashed blue), vertical advection (ADW in green), 813 freshwater flux (FWF in pink), vertical diffusion (DIFV in red), horizontal diffusion (DIFL in 814 dashed light blue), and entrainment (ENT in dashed green). The units are psu for a) and 815 psu.month ${ }^{-1}$ for b) and c). 
a) Salinity(NGoG)

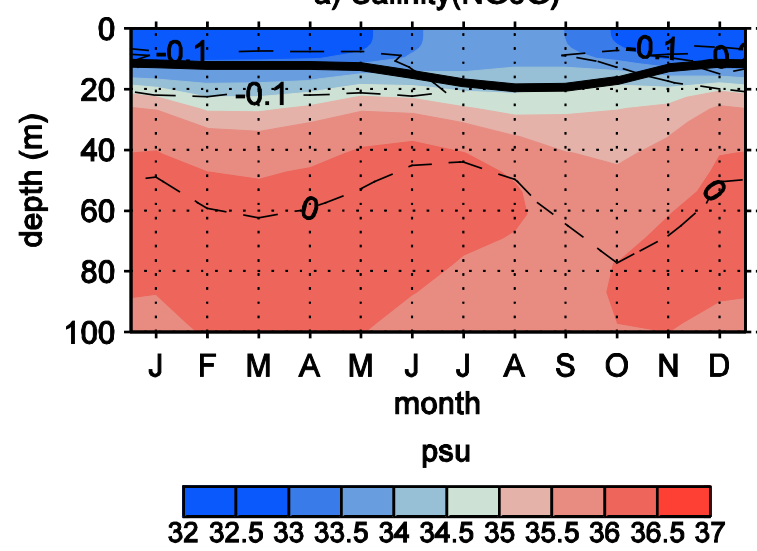

c) Horizontal Velocity (NGoG)
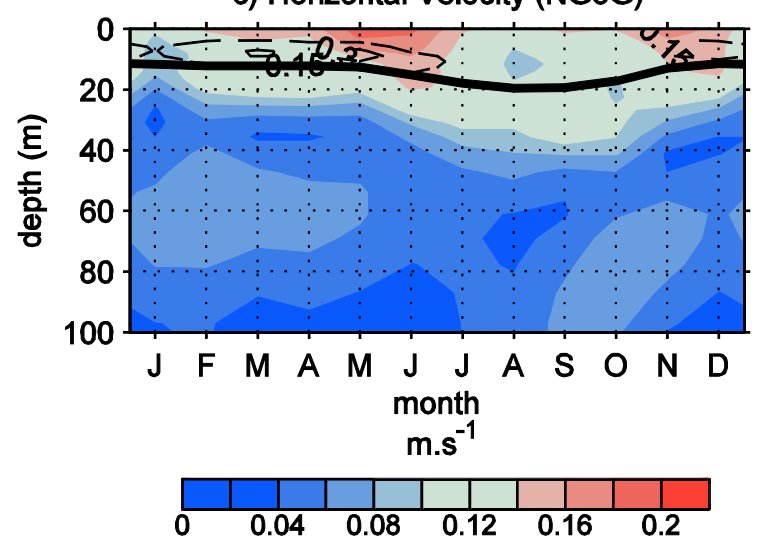

e) $\log _{10} \mathrm{Kz}$ (NGoG)

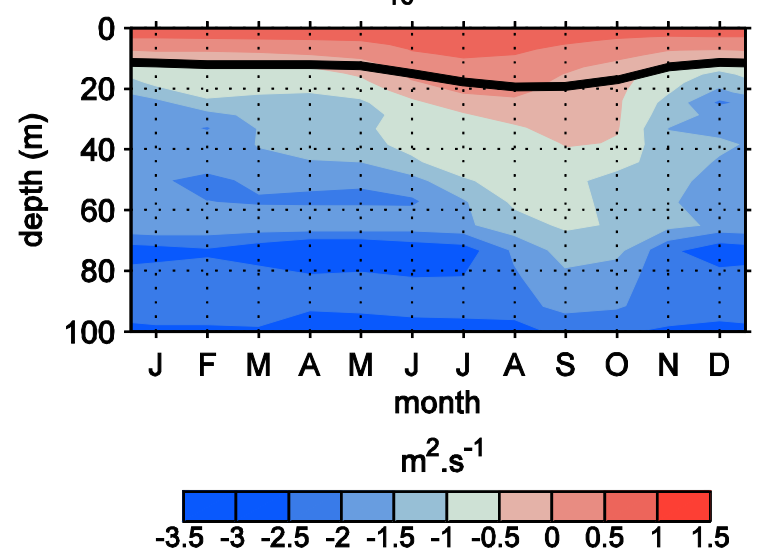

b) Vertical Velocity (NGoG)

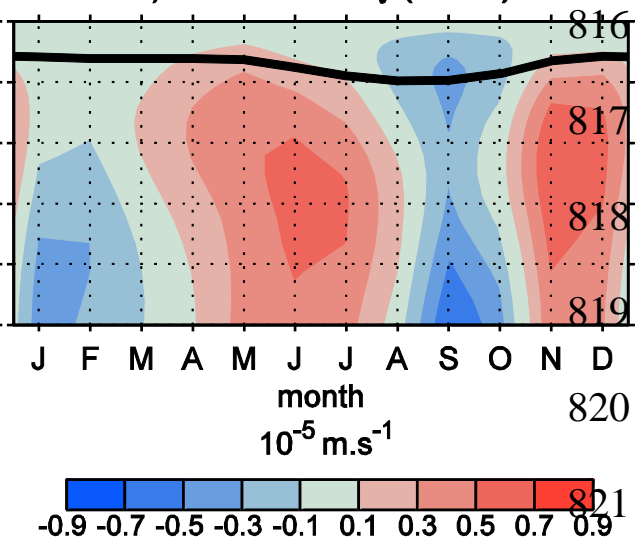

d) Wind Stress NGoG $\left(10^{-1}\right.$ N.m ${ }^{822}$

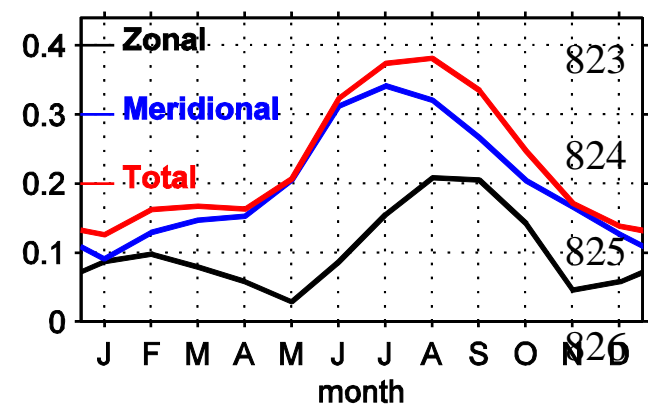

827

828

831

835 Figure 7. Seasonal evolution of vertical profiles for the NGoG region. a) Salinity (psu) and

836 vertical salinity gradient (dashed contours in psu.m ${ }^{-1}$ ). Contour intervals are 0.1 psu.m $\mathrm{m}^{-1}$. b)

837 Vertical velocity $\left(\mathrm{m} . \mathrm{s}^{-1}\right)$. c) Horizontal current speed $\left(\mathrm{m} . \mathrm{s}^{-1}\right)$ with square of vertical shear

838 (dashed contour in $\mathrm{s}^{-2}$ ). Contour intervals are $0.15 \mathrm{~s}^{-2}$. d) Wind stress (red is total, black is 
839 zonal, blue is meridional; N.m $\left.{ }^{-2}\right)$. e) Vertical diffusion coefficient $\left(\mathrm{m}^{-2} \cdot \mathrm{s}^{-1}\right)$. Thick black lines 840 indicate mixed- layer depths in a), b), c), and e). 

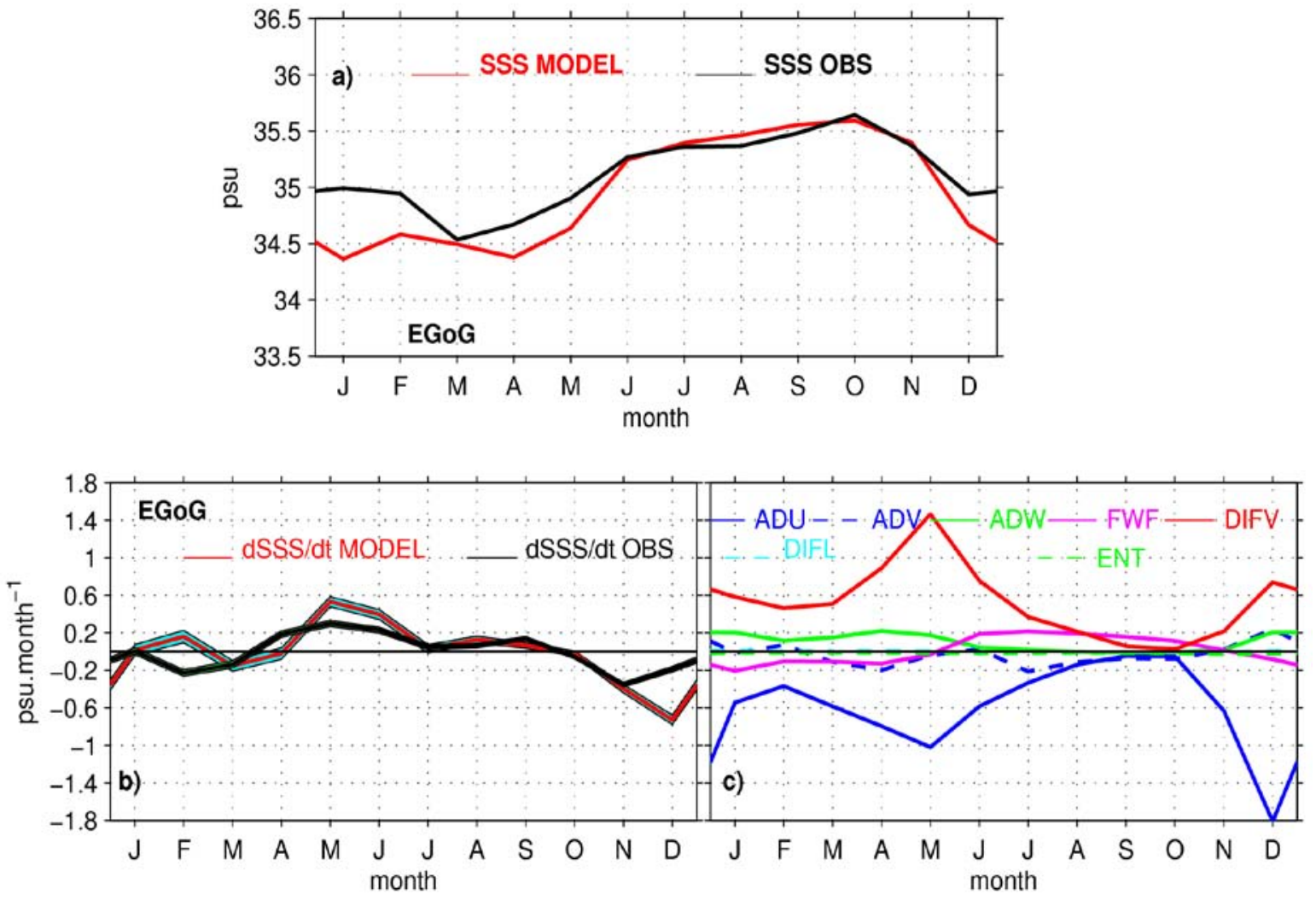

842

843

844 Figure 8. Same as Figure 6 but for the EGoG region.

845

846

847

848

849 
a) Salinity(EGoG)

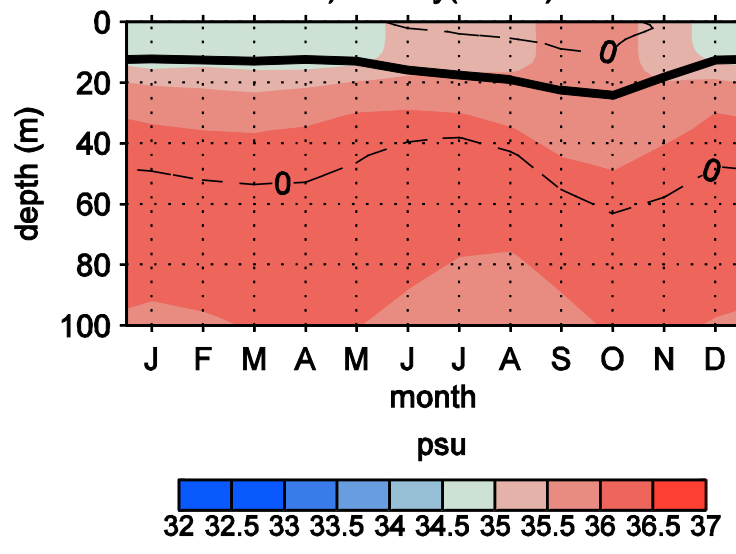

c) Horizontal Velocity (EGoG)

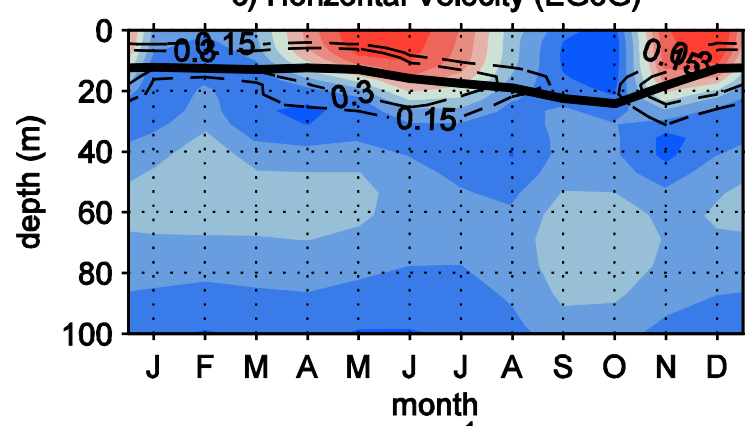

$\mathrm{m} \cdot \mathrm{s}^{-1}$

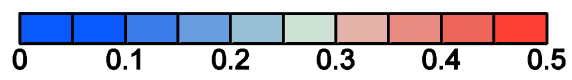

e) $\log _{10} \mathrm{Kz}$ (EGoG)

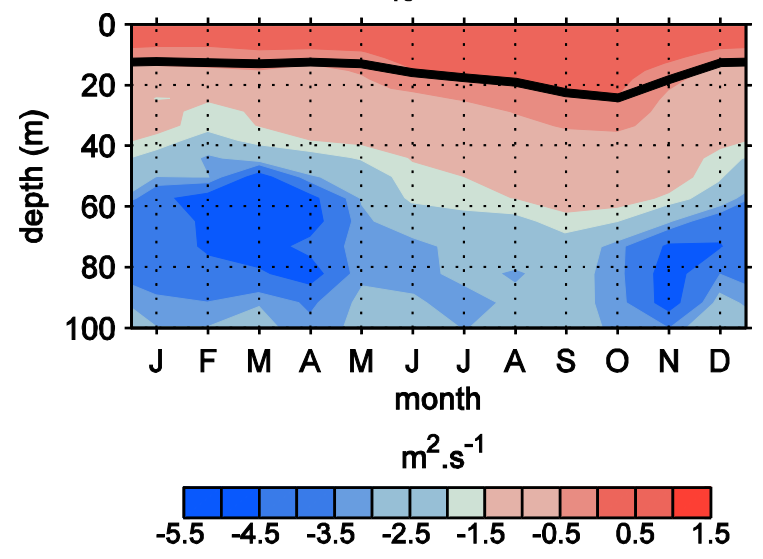

b) Vertical Velocity (EGoG)

850
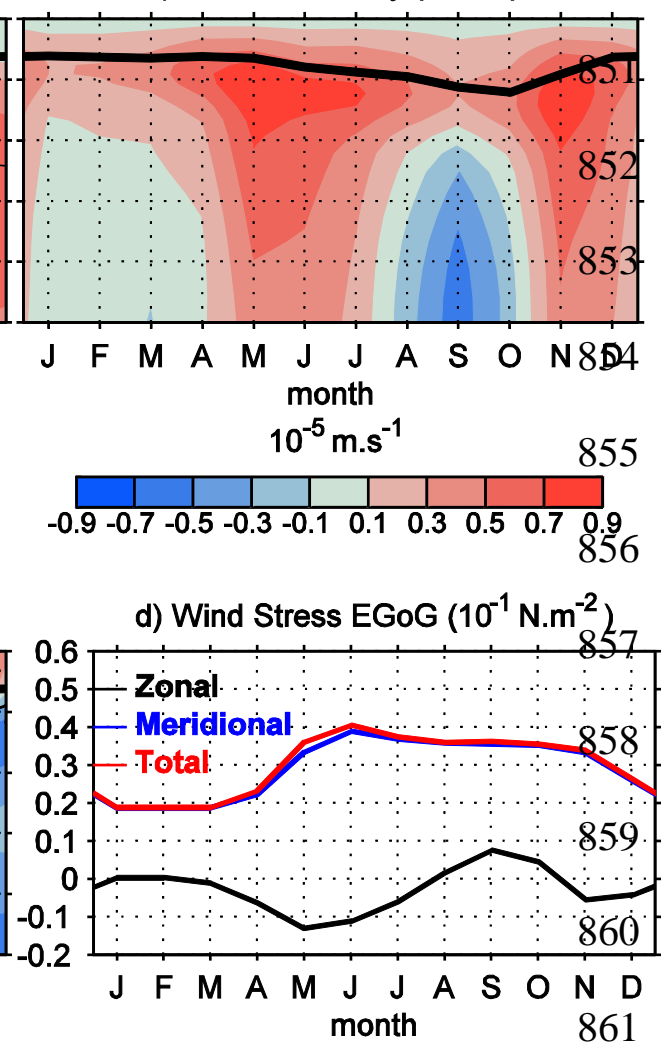

861

862

871 Figure 9. Same as Figure 7 but for the EGoG region. 

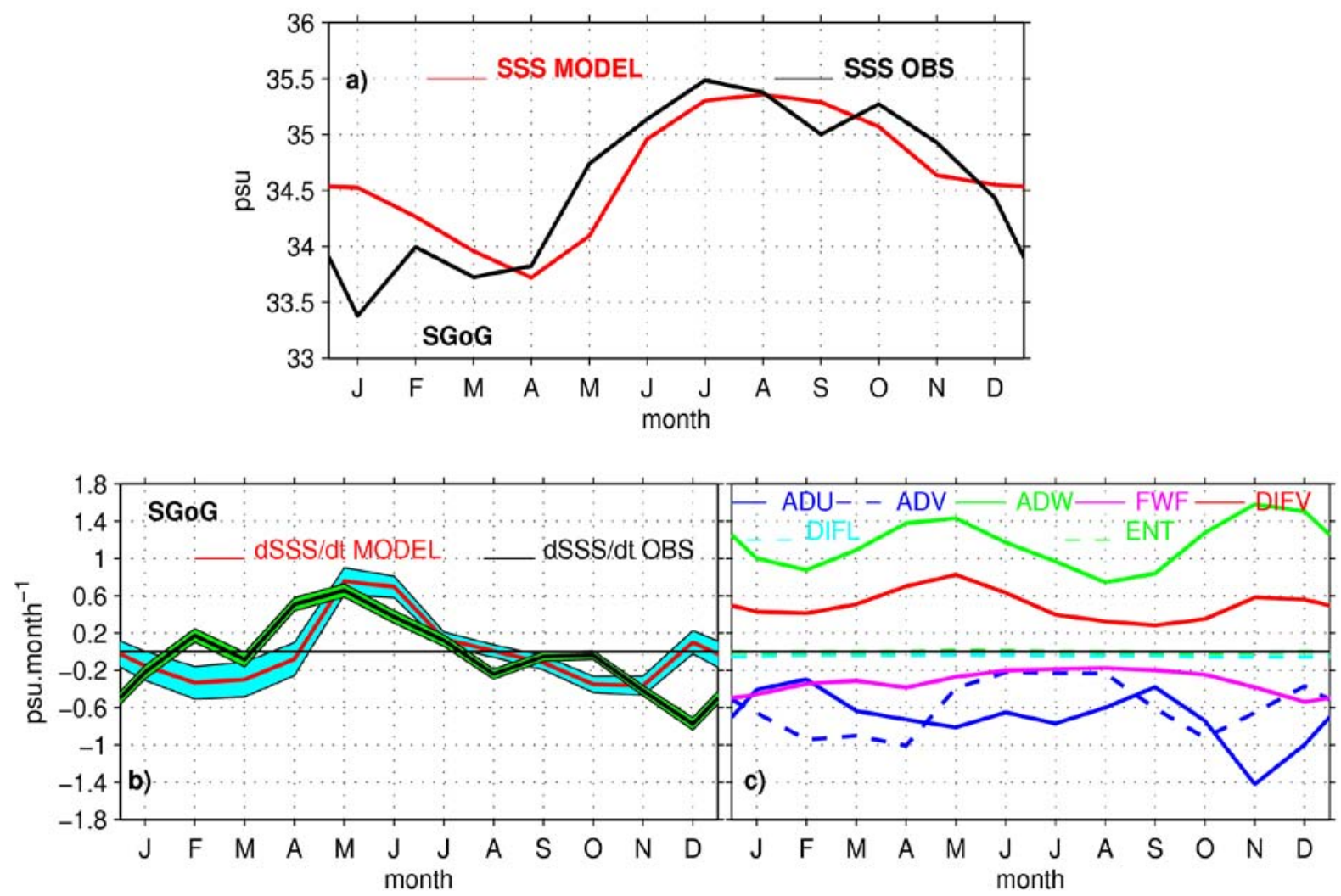

873

874

875

876 Figure 10. Same as Figure 6 but for the SGoG region.

877 
a) Salinity(SGoG)

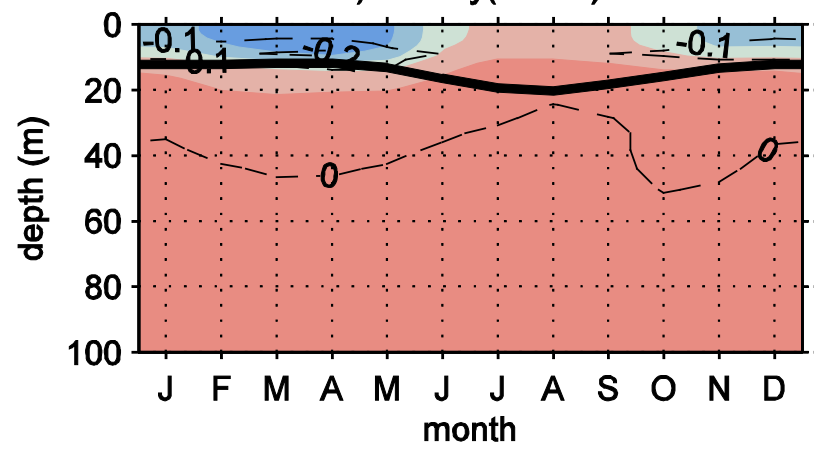

psu b) Vertical Velocity (SGoG)

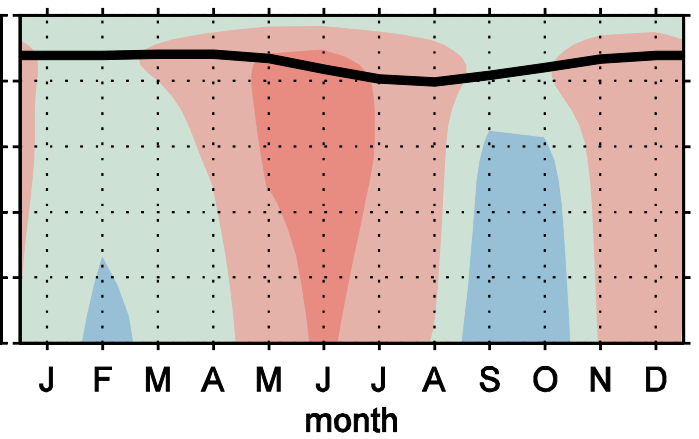

$10^{-5} \mathrm{~m} \cdot \mathrm{s}^{-1}$

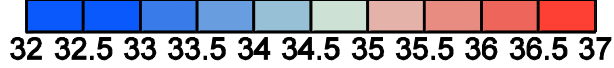
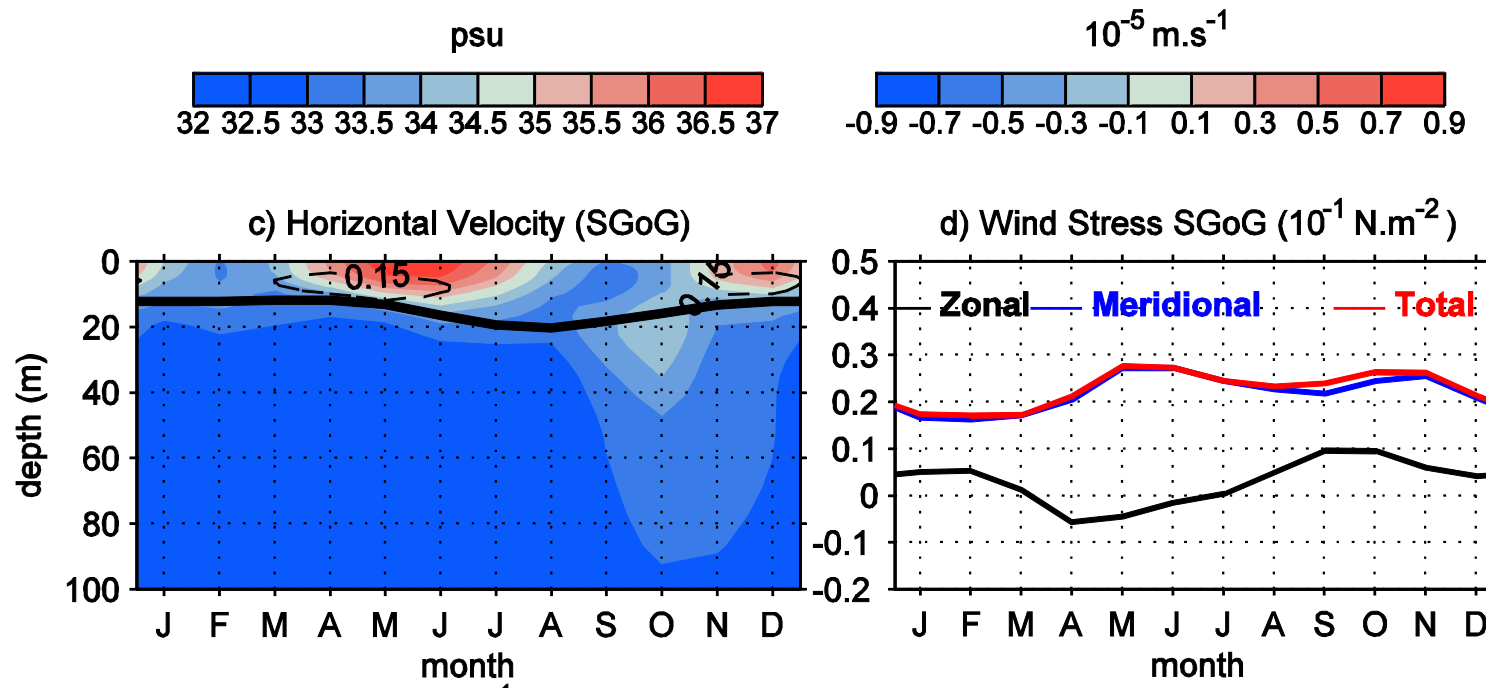

d) Wind Stress SGoG $\left(10^{-1} \mathrm{~N} \cdot \mathrm{m}^{-2}\right)$

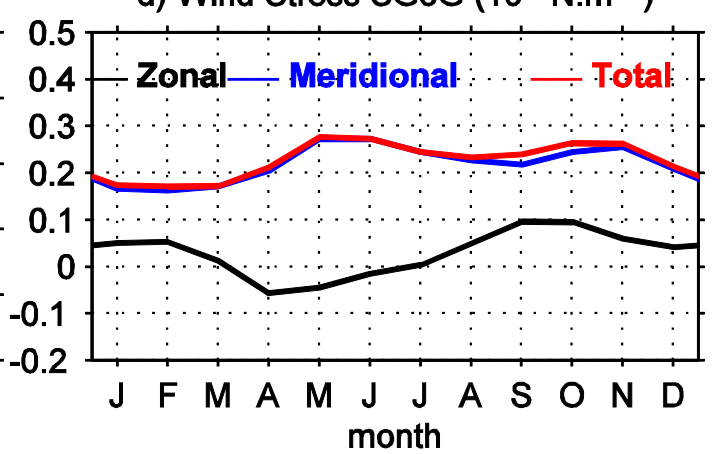

$\mathrm{m} \cdot \mathrm{s}^{-1}$

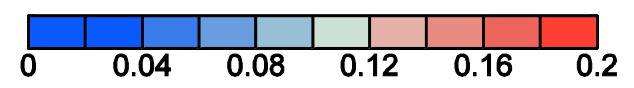

e) $\log _{10} \mathrm{Kz}$ (SGoG)

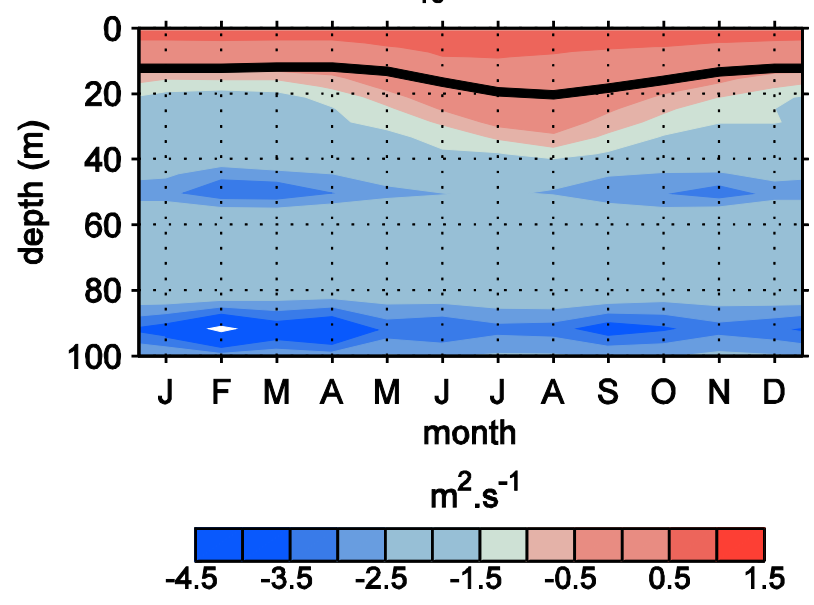

880 Figure 11. Same as Figure 7 but for the SGoG region. 

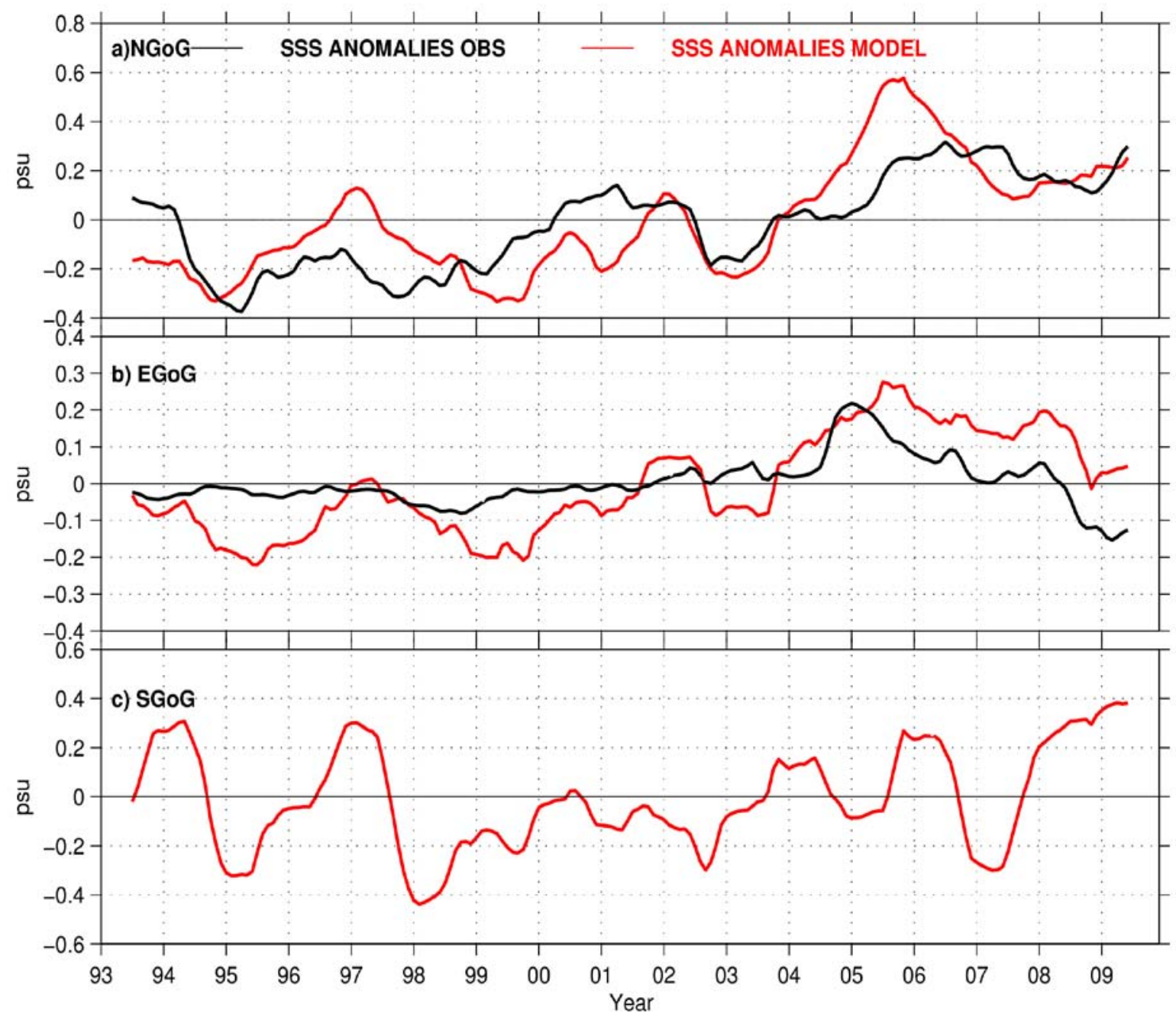

883

884 Figure 12. Time series of SSS interannual monthly anomalies for the observations (black)

885 and the model (red). Time series were averaged over the study boxes (NGoG, EGoG, and 886 SGoG). The mean seasonal cycle was removed and a one-year running mean was applied (due 887 to a deficiency in data for several locations). The units are psu.

888

889

890 


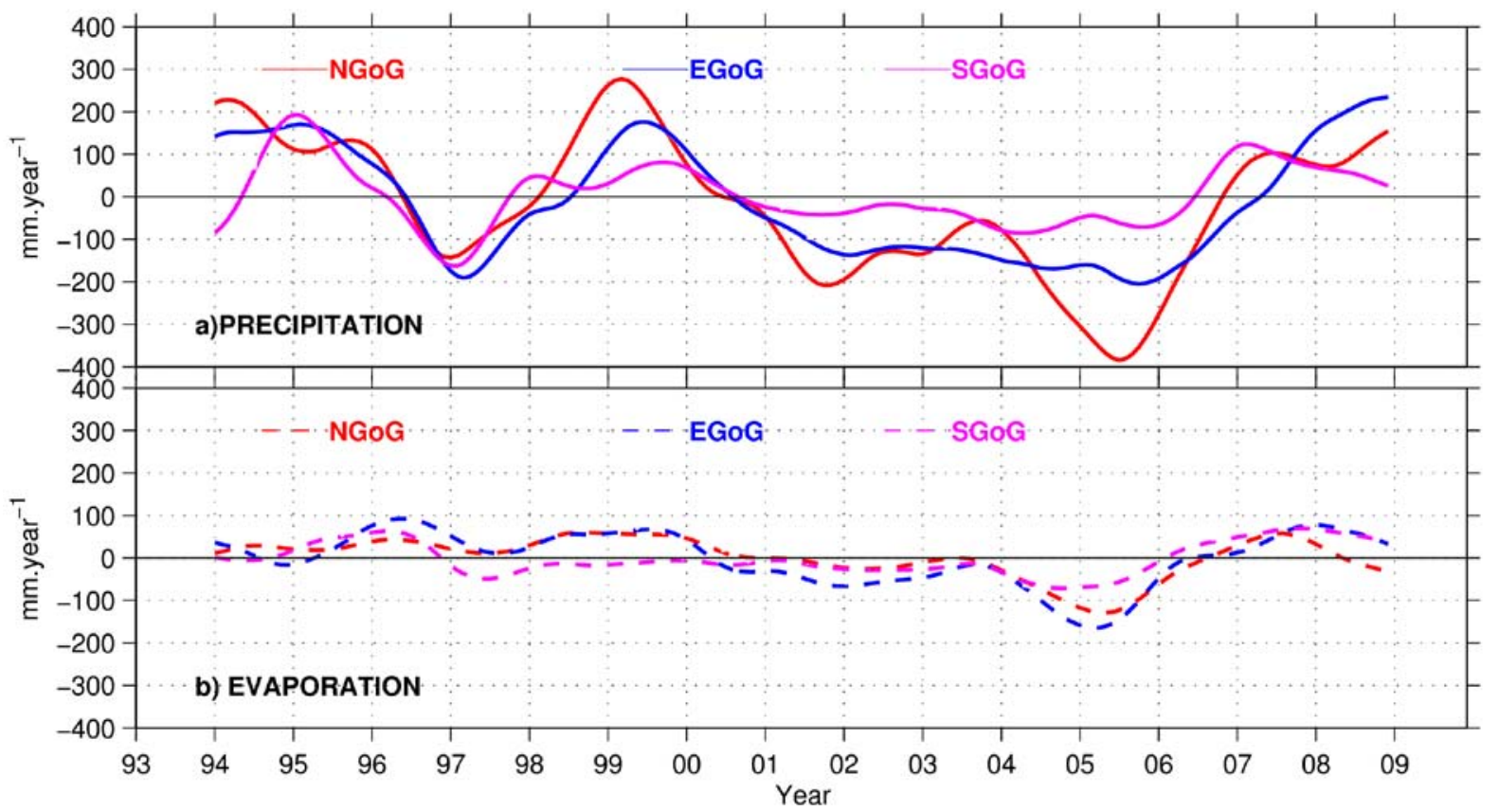

895 Figure 13. Interannual anomalies for 1993-2009 within the three study boxes: (a) for 896 precipitation and (b) for evaporation.

897 


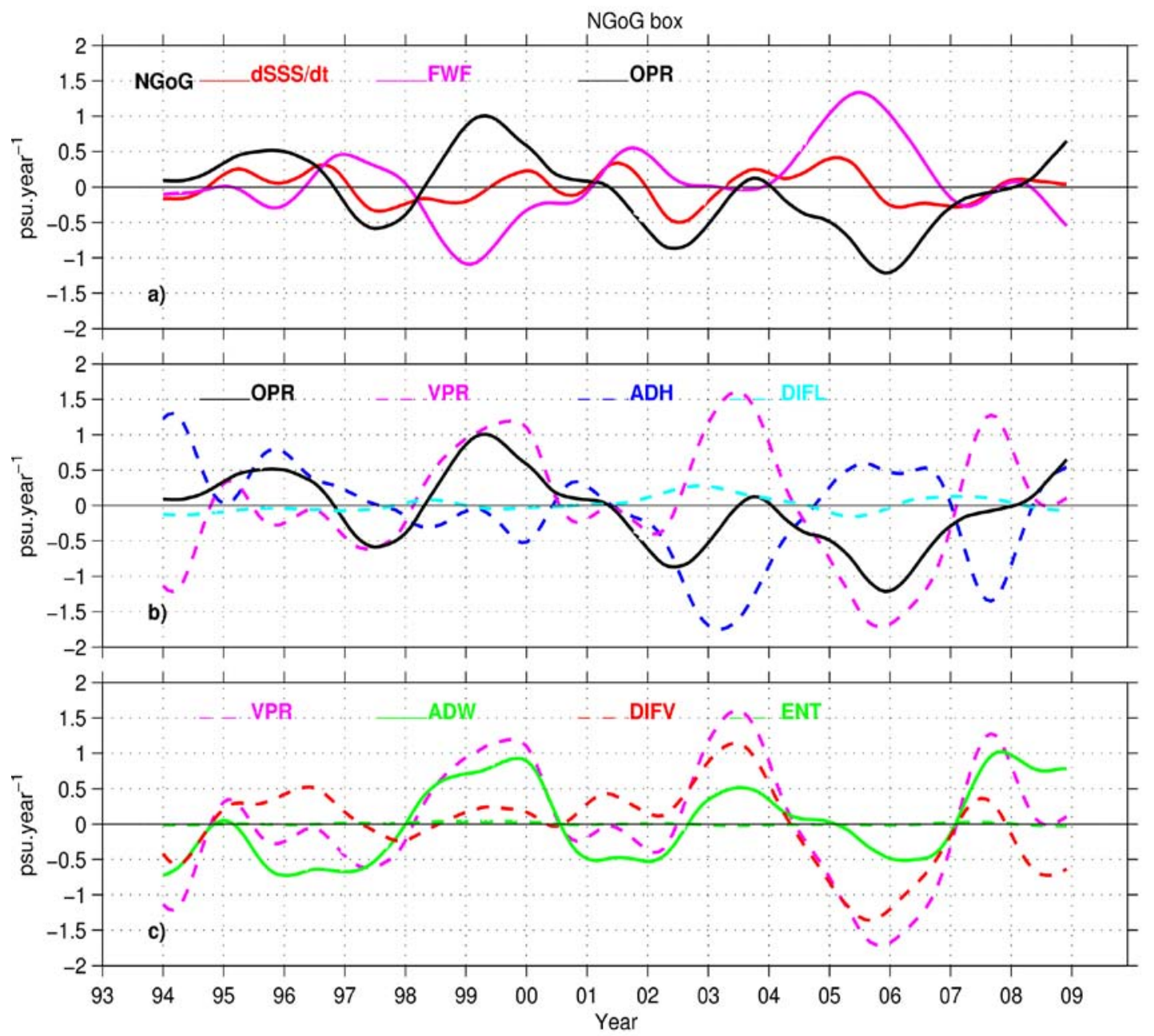

899 Figure 14. Interannual anomalies for 1993-2009 for the mixed-layer salinity balance in the

900 Northern Gulf of Guinea (NGoG) region: a) salinity tendency (red), freshwater flux (FWF,

901 pink), oceanic processes (OPR, black); b) Decomposition of oceanic processes: oceanic

902 processes (black, same as the black line in the panel (a)), vertical processes (VPR, dashed 903 pink), horizontal advection (ADH, dashed blue), and horizontal diffusion (DIFL, dashed light 904 blue); c) Decomposition of vertical processes: vertical processes (dashed pink, same as the 905 dashed pink line in the panel (b)), vertical advection (ADW, green), vertical diffusion (DIFV, 906 dashed red), and entrainment (ENT, dashed green). For all of the terms, the mean seasonal 907 cycle was removed and a 25-month Hanning Filter was applied. All of the terms are in 908 psu.year ${ }^{-1}$. 


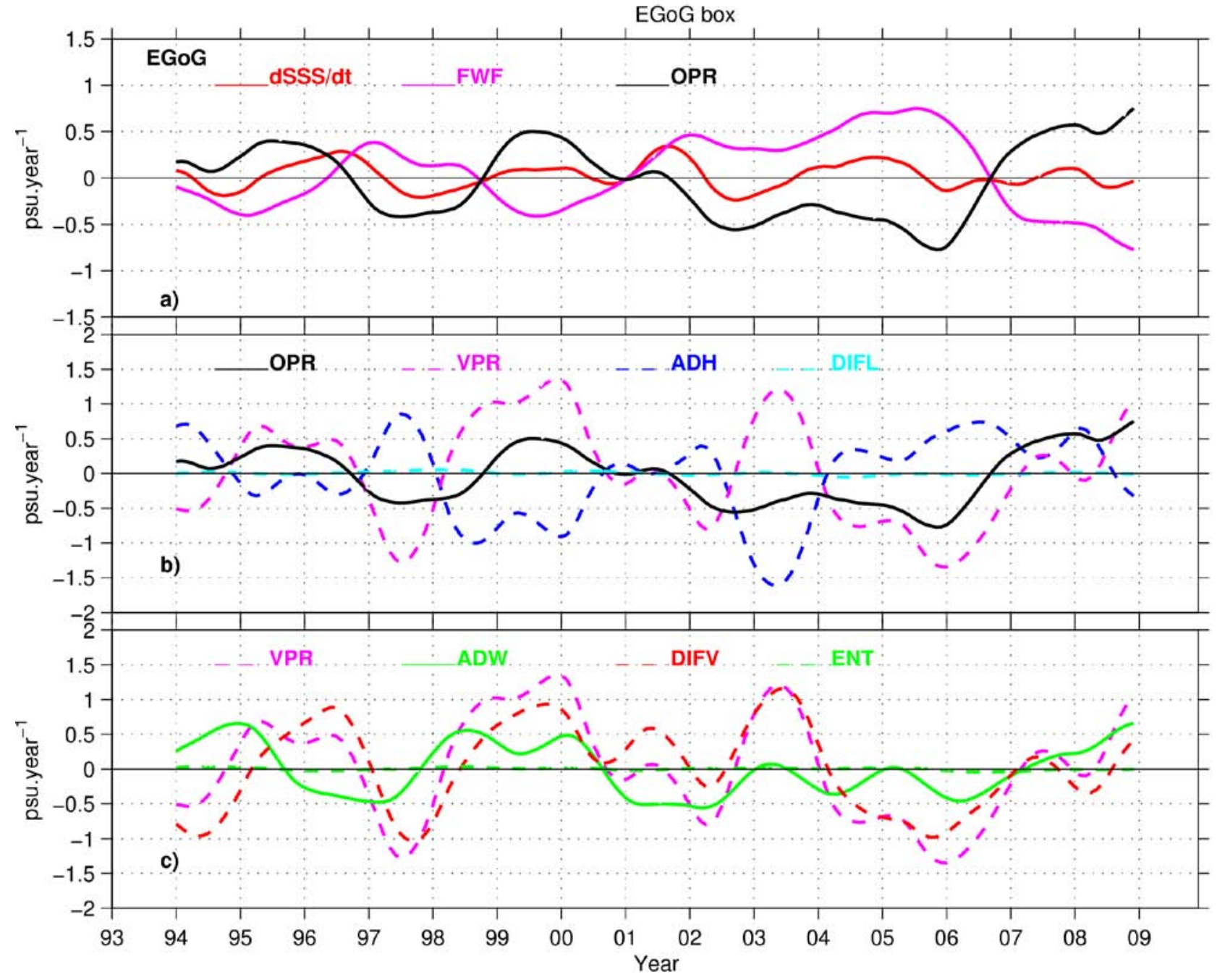

910

911

912

913

914 Figure 15. Same as Figure 14 but for the EGoG region.

915 


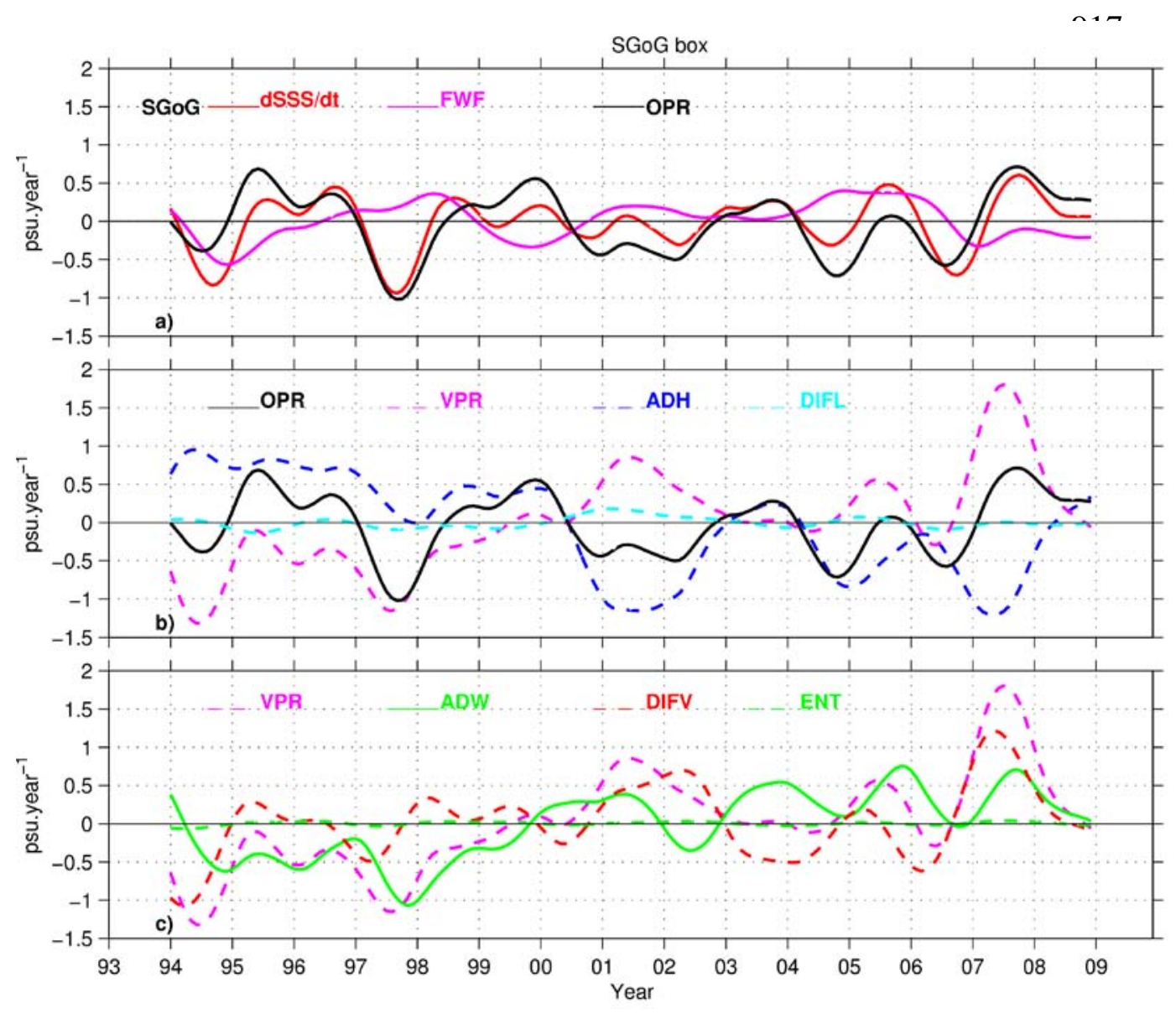

930

931 Figure 16. Same as Figure 14 but for the SGoG region. 


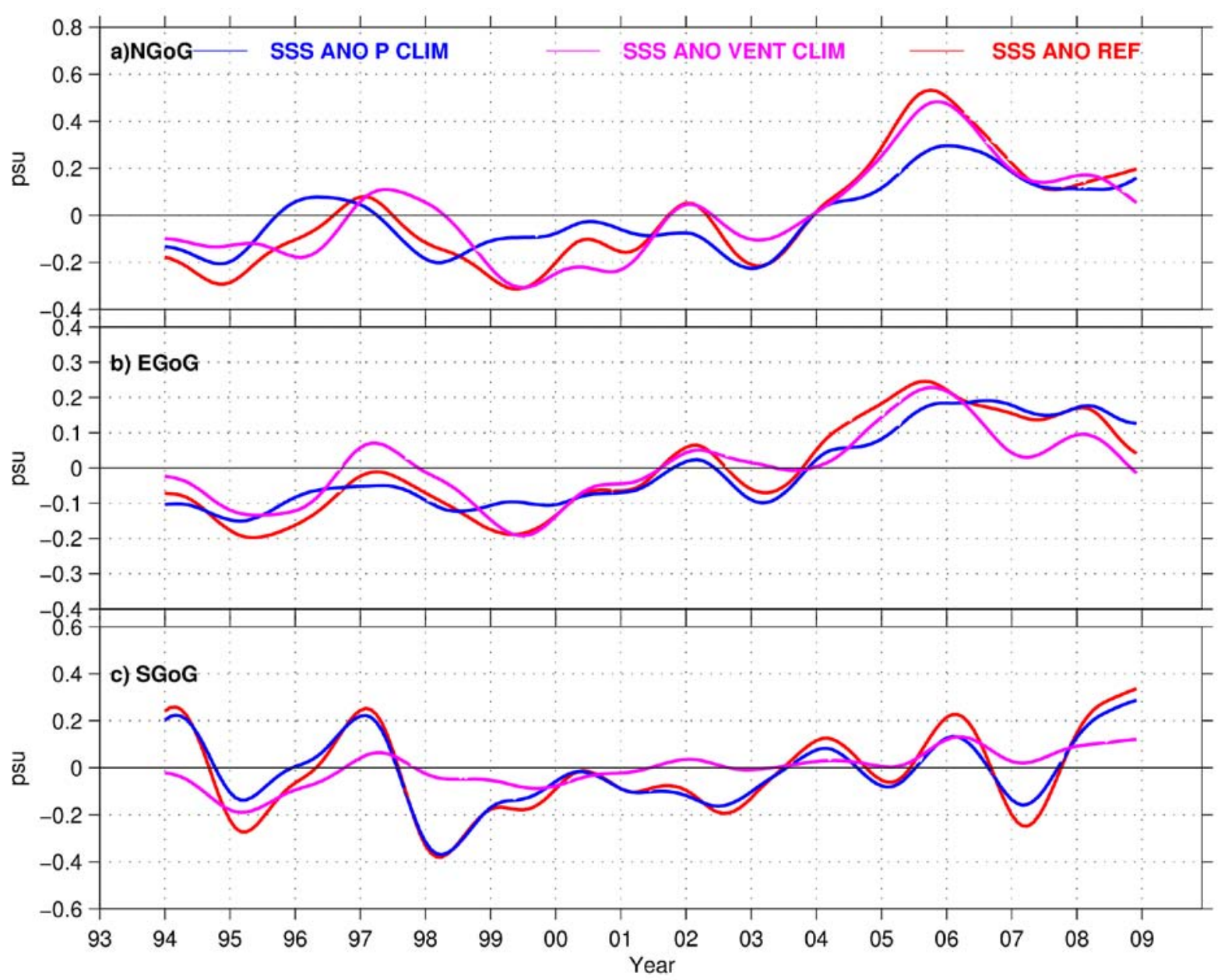

934

935 Figure 17. Time series of SSS interannual monthly anomalies for the reference simulation

936 (REF, red), the simulation with climatology precipitation (P CLIM, blue), and the simulation

937 with climatology winds (V CLIM, pink). Time series were averaged over the three study

938 boxes (NGoG, EGoG, and SGoG). The seasonal cycle was removed and a 25-month Hanning

939 Filter was applied. The units are psu.

940

941 